MITSUBISHI ELECTRIC RESEARCH LABORATORIES

https://www.merl.com

\title{
Concurrent Multiband Digital Outphasing Transmitter Architecture Using Multidimensional Power Coding
}

\author{
Chung, S.; Ma, R.; Shinjo, S.; Nakamizo, H.; Parsons, K.; Teo, K.H. \\ TR2015-004 January 15, 2015
}

\begin{abstract}
All-digital outphasing transmitter architecture using multidimensional power coding (MDPC) is proposed for non-contiguous concurrent multiband transmission with a high power efficiency. MDPC transforms multiband digital baseband signals into multi-bit low-resolution digital signals that drive switching-mode PAs. A prototype digital outphasing transmitter consists of two 1-GHz bandwidth GaN Class-D PAs and a Chireix power combiner. The two GaN PAs are driven by bipolar RF PWM signals, which are transformed from a concurrent dual-band LTE signal by MDPC. The dual-band LTE signal with 15-MHz aggregate channel bandwidth at $240 \mathrm{MHz}$ and $500 \mathrm{MHz}$ frequency band is transmitted with $-30 \mathrm{dBc}$ and $-37 \mathrm{dBc}$ out-of-band emissions, respectively. Digital outphasing achieves more than two times higher coding efficiency than conventional concurrent dual-band digital transmitters with the same PAs in Class-S operation. Measured power coding efficiencies of $35.4 \%$ and $47.1 \%$ are observed with outphasing bipolar and 3-level RF PWM signals respectively, which are encoded from the dual-band LTE signal.
\end{abstract}

IEEE MTT Transaction, PA Special Issue

(C) 2015 MERL. This work may not be copied or reproduced in whole or in part for any commercial purpose. Permission to copy in whole or in part without payment of fee is granted for nonprofit educational and research purposes provided that all such whole or partial copies include the following: a notice that such copying is by permission of Mitsubishi Electric Research Laboratories, Inc.; an acknowledgment of the authors and individual contributions to the work; and all applicable portions of the copyright notice. Copying, reproduction, or republishing for any other purpose shall require a license with payment of fee to Mitsubishi Electric Research Laboratories, Inc. All rights reserved. 



\title{
Concurrent Multiband Digital Outphasing Transmitter Architecture Using Multidimensional Power Coding
}

\author{
SungWon Chung, Member, IEEE, Rui Ma, Member, IEEE, Shintaro Shinjo, Senior Member, IEEE, \\ Hideyuki Nakamizo, Member, IEEE, Kieran Parsons, Senior Member, IEEE, and \\ Koon Hoo Teo, Member, IEEE
}

\begin{abstract}
All-digital outphasing transmitter architecture using multidimensional power coding (MDPC) is proposed for non-contiguous concurrent multiband transmission with a high power efficiency. MDPC transforms multiband digital baseband signals into multi-bit low-resolution digital signals that drive switching-mode PAs. A prototype digital outphasing transmitter consists of two 1-GHz bandwidth GaN Class-D PAs and a Chireix power combiner. The two GaN PAs are driven by bipolar RF PWM signals, which are transformed from a concurrent dual-band LTE signal by MDPC. The dual-band LTE signal with 15- $\mathrm{MHz}$ aggregate channel bandwidth at $240 \mathrm{MHz}$ and $500 \mathrm{MHz}$ frequency band is transmitted with $-30 \mathrm{dBc}$ and $-37 \mathrm{dBc}$ out-of-band emissions, respectively. Digital outphasing achieves more than two times higher coding efficiency than conventional concurrent dual-band digital transmitters with the same PAs in Class-S operation. Measured power coding efficiencies of $35.4 \%$ and $47.1 \%$ are observed with outphasing bipolar and 3-level RF PWM signals respectively, which are encoded from the dual-band LTE signal.
\end{abstract}

Index Terms - Class-S power amplifier, concurrent dual-band transmitter, inter-band carrier aggregation, power coding, multiband delta-sigma modulator, outphasing.

\section{INTRODUCTION}

$\mathrm{N}$ ON-CONTIGUOUS concurrent multiband transmission techniques for inter-band carrier aggregation (CA) [1] have been recently developed for 4G LTE-A and 5G mobile broadband communication, which achieve a multi-gigabit wireless data rate as well as efficient spectrum usage. The flexibility and demanding performance requirements for the

Manuscript received September 1, 2014; revised November 19, 2014 and December 28, 2014; accepted December 28. Date of publication January, 2015; date of current version December 29, 2014.

S. Chung was with Mitsubishi Electric Research Laboratories, Cambridge, MA 02139 USA. He is now with the Department of Electrical Engineering, University of Southern California, Los Angeles, CA 90089 USA, and also with the Microsystems Technology Laboratories (MTL), Massachusetts Institute of Technology, Cambridge, MA 02139 USA (e-mail: sungwon@ieee.org).

S. Shinjo and H. Nakamizo are with Mitsubishi Electric Corporation, Information Technology R\&D Center, Ofuna, Kamakura 247-8501 Japan.

R. Ma, K. Parsons, and K. H. Teo are with Mitsubishi Electric Research Laboratories, Cambridge, MA 02139 USA (e-mail: rma@merl.com).

Color versions of one or more of the figures in this paper are available online at http://ieeexplore.ieee.org.

Digital Object Identifier 10.1109/TMTT

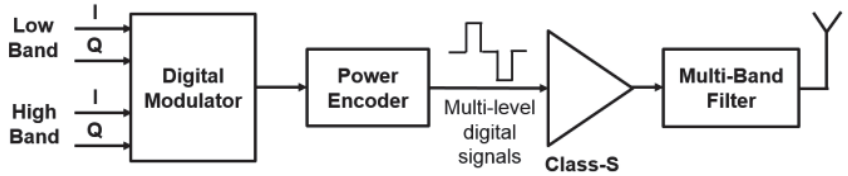

Fig. 1. All-digital transmitter architecture for concurrent multi-band transmission.

inter-band CA are very challenging to achieve. Furthermore, the peak-to-average power ratio (PAPR) of a concurrent multiband signal is typically larger than $10-12-\mathrm{dB}$, so that the average power efficiency of a linear power amplifier (PA) significantly suffers.

All-digital concurrent multiband RF transmitters [2]-[5] with Class-S operation have shown a promising potential to provide high average power efficiency. All-digital architecture (Fig. 1) replaces RF/analog front-ends, which drive the PA in Class-S operation, with high-speed digital circuits, allowing a compact and low-cost implementation. Class-S operation demonstrated in [6]-[10] typically achieves the output envelope amplitude modulation with a switching-mode Class-D amplifier by applying time-domain modulation on the two-level digital input signals. Pulse-width modulation (PWM) [6], [7] and bandpass delta-sigma modulation (BPDSM) [8]-[10] have been popularly used to modulate the digital input signal for Class-S operation. Although ideal Class-S operation achieves 100\% power efficiency independent of power back-off [9], the non-ideal switch characteristics of a transistor at a high frequency, particularly when the input pulses have a large variation in duty cycle, degrades the power efficiency.

The average power efficiency of an ideal Class-S transmitter, as reviewed in Section II-A, can be determined as a product of the PA peak power efficiency and power coding efficiency, which is defined as a ratio of the in-band power to the total output power both at the transmitter output [11]-[13], [37]. Compared to the linear PAs [14]-[16] whose average power efficiency depends on the instantaneous envelope amplitude of the RF signals in transmit, the power efficiency of an ideal Class-D PA in Class-S operation remains constant. Therefore, to improve the average power efficiency of all-digital concurrent multiband transmitters, it is essential to improve power coding efficiency. With Class-S outphasing transmitters, 


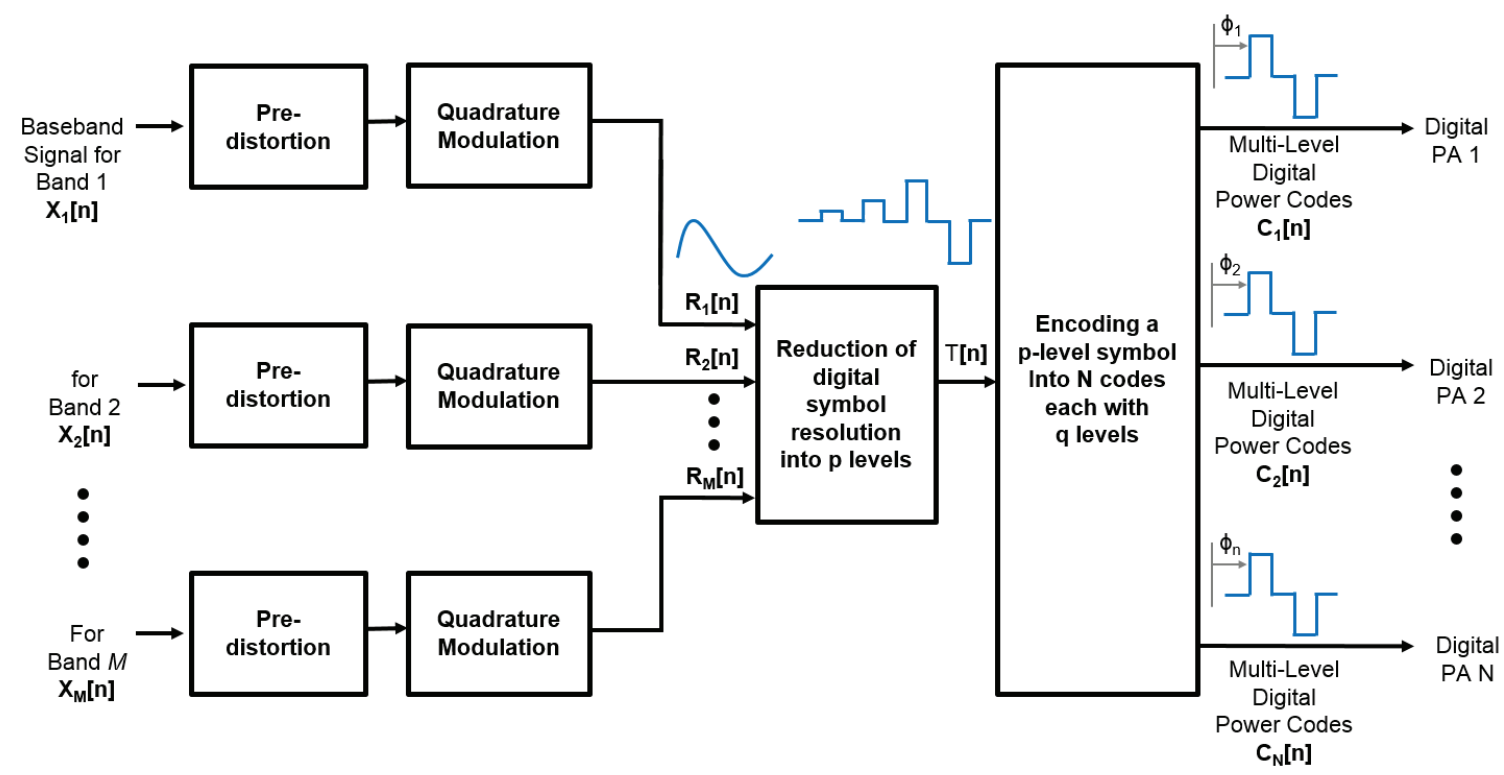

Fig. 2. Multidimensional power coding (MDPC) for concurrent multi-band digital transmitters.

the outphasing operation varies the PA power efficiency depending on the transmitter output power, so that power combiner design is very important to achieve high average power efficiency.

To improve the power coding efficiency of all-digital Class-S transmitters, various pulse modulation techniques have been introduced. Multilevel RF PWM (ML-RFPWM) [10], [18], [19] provides a high coding efficiency with moderate out-of-band emission. Multilevel baseband delta-sigma modulation (DSM) followed by a quadrature modulation [2] and multilevel RF delta-sigma modulation (ML-RFDSM) [18] generally achieves lower out-of-band emission than RF PWM if the ML-RFDSM oversampling rate is sufficiently high. The coding efficiency of ML-RFDSM is, due to noise shaping, lower than ML-RFPWM. Nevertheless, ML-RFDSM provides an advantage that it can use a lower sampling clock rate than ML-RFPWM. Multilevel IF PWM (ML-IFPWM) [19] compromises the high coding efficiency of ML-RFPWM and the low out-of-band emission of ML-RFDSM, but with additional spurious tones that prevent the application of ML-IFPWM on concurrent multiband transmission. Combining baseband delta-sigma (DSM) modulation and baseband PWM [20], [21] shows the advantage of both techniques: a low oversampling rate is allowed while a low out-of-band emission is achieved. When the baseband DSM-PWM signals are up-converted to a carrier frequency using a digital mixer, however, these hybrid DSM-PWM transmitters would generate in-band spurious tones if a concurrent multiband signal is transmitted. Bandpass delta-sigma modulation (BPDSM) does not generate such harmful spurious tones when a concurrent multiband signal is transmitted. Due to the complexity of multi-level Class-S PA implementation, multi-level BPDSM has been limited to less than 3-level in practice [3], [5], [22] resulting in low power coding efficiency. Recently, a hybrid DSM-RFPWM architecture [32] is reported, which avoids the in-band spurious tones by directly transforming a DSM signal into a RFPWM signal without frequency up-conversion. However, since the DSM-RFPWM technique is developed for a classical switching-mode PAs with a binary input, achieving a high average power efficiency still remains as an unsolved problem.

This work introduces a digital outphasing transmitter architecture, which is based on a hybrid architecture taking the advantage of BPDSM, RFPWM, and outphasing. Digital outphasing improves the average power efficiency of concurrent multiband transmitters while addressing the aforementioned design challenges of advanced digital transmitters. The proposed architecture modulates multiband baseband signals into a multilevel BPDSM signal, which is then transformed into an RFPWM signal with a reduced number of amplitude levels. The number of amplitude levels in the RFPWM signal is further reduced by digital outphasing. The key difference of the digital outphasing in this work from classical outphasing is that only a small number of discrete outphasing angles are used and also a large outphasing angles never occur, allowing the use of a highly efficiency Chireix power combiner.

This paper extends the work of digital outphasing transmitter architecture [23] in a number of aspects. First, we implemented and characterized a prototype concurrent dual-band digital outphasing transmitter including GaN Class-D PAs in Class-S operation. Second, we introduce multidimensional power coding (MDPC) theory, which is a framework that allows the optimization of the proposed digital outphasing transmitter architecture as well as general advanced transmitter architectures with a high degree-of-freedom in modulation. Additionally, we discuss general considerations on the design trade-offs in terms of linearity and coding efficiency.

The organization of this paper is as follows. Section II introduces the MDPC framework. Section III describes the digital outphasing transmitter architecture based on MDPC for non-contiguous concurrent multi-band transmission, with 


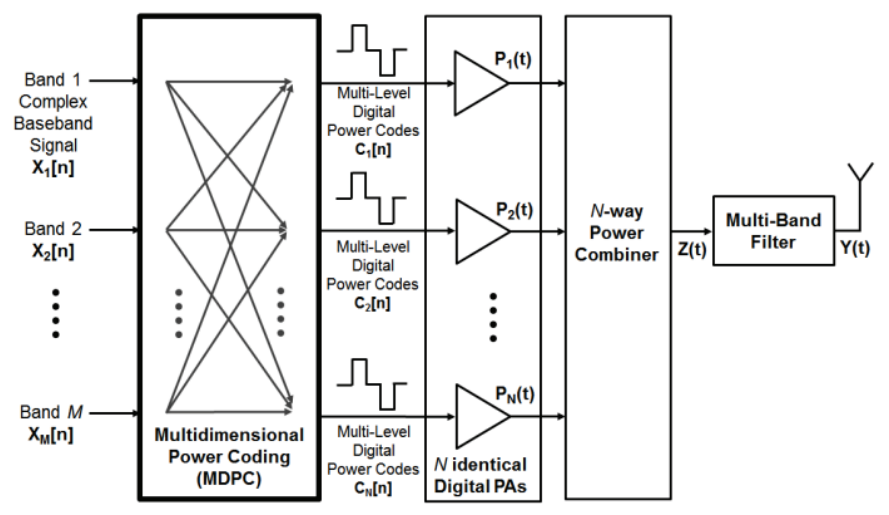

Fig. 3. A typical architecture of MDPC-based concurrent multiband digital transmitters with $\mathrm{N}$-way power combining.

considerations on RF output filter design requirements and transmitter average power efficiency. Section IV discusses the measurement results with $800-\mathrm{MHz}$ GaN Class-D PAs, concluding in Section V.

\section{Multidimensional POWER CODING (MDPC)}

The concept of power coding, which we introduce in this paper, serves as a theoretical framework to improve the general performance matrix of digital transmitters such as power efficiency, error-vector magnitude (EVM), ACPR (adjacent channel power ratio), and spurious emission. A power coding scheme was used in [19] with a single Class-S PA but has not been explored to connect the definition of a given coding scheme to digital transmitter performance elements such as coding efficiency, soft switching, distortion, linearity, and noise. It is beyond the scope of this paper to create this connection, which will allow the system designers to systematically optimize the efficiency of a particular power coding scheme by considering a specific set of transmitter performance goals. Instead, as a first step towards the further development of power coding theory, we formulate the implementation structure of a power coding scheme in what follows.

Multidimensional power coding (MDPC) for concurrent multi-band transmitters transforms $M$ baseband signals into $N$ multi-level digital RF signals (Fig. 2). The $M$ baseband signals correspond to $M$ concurrently transmitted wireless channels. Each of the $N$ multi-level digital RF signals drives a digital PA. In principle, MDPC transforms multiple baseband signals into a set of digital signals that interface with digital PAs.

MDPC performs four functions in order - 1) digital predistortion on each of the multiple baseband signals to be concurrently transmitted, 2) frequency up-conversion of multiple baseband signals into a single-stream multiband digital RF signals, 3) reduction of the digital RF signal resolution, and 4) encoding the low-resolution digital RF signal into power codes. To simplify matters, assume that crosstalk and memory effects with the PAs do not exist for the following discussion.

Fig. 3 shows a typical architecture of MDPC-based concurrent multiband digital transmitters. The $N$ outputs from the digital PAs are combined, producing a concurrent multi-band signals. Each digital PA can transmit an independent signal, providing an additional degree-of-freedom in modulation. The multi-band filter after the power combiner is optional, suppressing out-of-band emission if necessary. With $N$-way power combining, assuming that the power combiner has ideal characteristics of zero insertion loss and infinite bandwidth, [24] shows that the average transmitter power efficiency improves beyond the classical 2-way outphasing [25], [26], but with diminishing efficiency improvement as $N$ increases. For example, when $N=2$, two 2-level digital PAs are equivalent to one 3-level digital PA if the two power codes from each PA are synchronized as in [19]. Under the MDPC framework, if the phase difference between the two power codes is properly outphased, the two 2-level digital PAs can achieve approximately three times higher average power efficiency than one 3-level digital PA. With an experimental prototype transmitter, we show that this average power efficiency improvement is large enough to compensate for power combiner loss.

The transmitter architecture for MDPC is not limited to this specific example. MDPC can be applied to general transmitter architectures with multiple degree-of-freedoms in RF envelope modulation, such as phased-array transmitters, envelope tracking transmitters, and polar transmitters.

\section{A. Frequency up-conversion}

The frequency up-conversion is performed by quadrature modulation on an RF carrier $f_{m}$ with the complex digital baseband signal $X_{m}[n]$, so that the resulting multiband digital RF signal is obtained as

$$
R_{m}[n]=X_{m}[n] e^{j 2 \pi f_{m} / f_{s}}
$$

where $f_{s}$ is the sampling clock rate of an MDPC encoder. Although a practical hardware implementation requires up-sampling of baseband signal before the quadrature modulation, we assume the all signals have the same sampling rate to understand the system with simple equations.

\section{B. Reduction of Digital RF Signal Resolution}

The reduction of digital signal resolution is essential to drive the digital PAs whose input signal has a limited resolution. Due to the complexity and parasitic capacitance, the number of output levels with a digital PA particularly for a high-power basestation is practically limited to no more than 5 or 7 levels. The resolution of the digital PA input signal (typically 1-3 bits) is most likely much lower than the resolution of the complex digital baseband signal (typically more than 10-12 bits for power control with mobile communication signals such as WCDMA and LTE).

Reduction of the digital RF signal resolution is performed by a nonlinear oversampling. Delta-sigma modulation is one function that can serve as the oversampling function. As a result, the low-resolution multi-band digital RF signal $T[n]$, which includes quantization noise $Q(t)$, is obtained from the high-resolution digital RF signal $R_{m}[n]$ : 


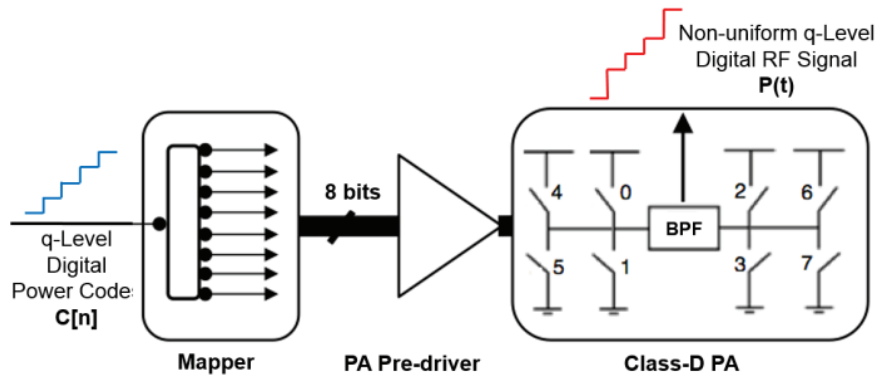

(a)

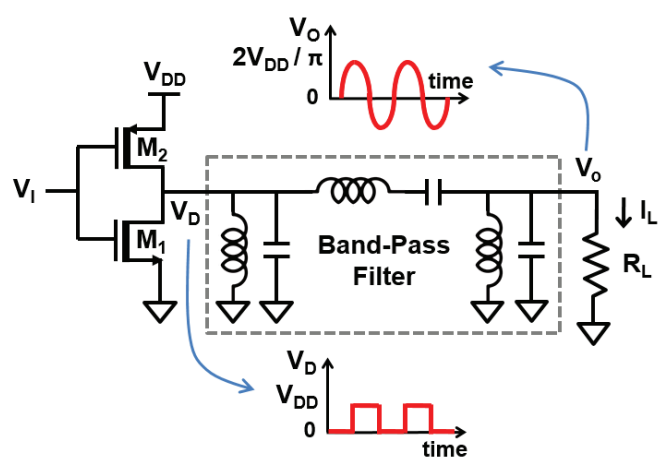

(b)

Fig. 4. Digital Class-S transmitter: (a) non-uniform multilevel digital PA in Class-S operation, which provides higher coding efficiency than uniform multilevel digital PAs, (b) a single-bit Class-S transmitter implementation, consisting of a Class-D PA followed by an LC band-pass filter (BPF).

$$
T[n]=Q[n]+\sum_{m=1}^{M} R_{m}[n]
$$

The multi-band filter attenuates the added quantization noise to a required level, so that the radiated signal through the antenna does not increase the receiver band noise. Therefore, when the digital PAs and power combiner have ideal characteristics of infinite bandwidth without nonlinearity, the impulse response of the multi-band analog filter $h(t)$ can be chosen such that the filter output is close to the in-band signal before reducing the signal resolution:

$$
E_{p}=\sum_{n}\left|R[n-\tau]-y\left(n T_{e}\right)\right|^{2} \ll \sum_{n}|R[n]|^{2}
$$

where $y(t)$ is the multi-band filter output, $T_{e}$ is the power encoder output sampling time, and $\tau$ is a delay to align the high-resolution digital RF signal $R[n]=\sum_{m=1}^{M} R_{m}[n]$ and the multiband filter output $y(t)$.

\section{Encoding the Low-Resolution Digital RF Signal}

Power code is a set of digital signals, which represents a power level at the transmitter output. For example, if the 8 switches of the Class-S PA (Fig. 4a) have a set of states - \{on, off, off, on, on, off, off, on\}, the output power with the largest amplitude is produced.

Encoding the digital RF signal into power codes is allowed only when the resolution of the digital RF signal is low enough such that a mapping can be found from each value of the digital RF signal $T[n]$ to a set of power codes:

$$
C_{i}[n]=M_{i}(T[n])
$$

where $M_{i}$ is the mapping function.

A general mapping function can be either linear or nonlinear. Popularly chosen coding functions include multi-level delta-sigma modulation, multi-level PWM, and combinations of both, depending on application requirements. A general mapping function is not limited to these typical cases, but can be arbitrarily designed to improve a specific transmitter performance factor such as efficiency, bandwidth, and linearity.

\section{Linearization}

In power coding, the linearization by digital-predistortion (DPD) on the digital baseband signals is necessary to compensate for a nonlinear mapping function as well as the static and dynamic nonlinearities of the digital PAs. The PA dynamic nonlinearities and crosstalk are not considered in this paper to simplify details. We consider two purposeful cases of using a nonlinear coding function.

First, popular pulse modulation techniques are inherently nonlinear, so that the use of a nonlinear mapping function is often inevitable. For an example, if RFPWM codes are driving the digital PAs, because the envelope amplitude of switching-mode PA output is nonlinearly proportional to the duty cycle as studied in [27], [28], the baseband digital signal $X_{m}[n]$ needs to be properly pre-distorted.

Second, a digital PA with non-uniform multilevel output (Fig. 4a) achieves a higher averaging coding efficiency, compared to a digital PA with uniform multilevel output. To drive the non-uniform multilevel digital PA, a nonlinear mapping function is necessary. A specific non-uniformity can be optimized considering the statistical property of transmit signals. DPD on the digital baseband signals compensates for this purposefully added static nonlinearity.

Behavioral simulation shows approximately 5\% coding efficiency improvement with an H-bridge digital PA by using non-uniform multilevel outputs. The coding efficiency is simulated for 5-MHz bandwidth LTE signal transmission with 5-level IFPWM power coding [2]. Variation on the transistors in term of size and supply voltage, results in different current and voltage ratios between the two adjacent non-zero output levels of the digital PA.

A predistortion function $F[n]$ is applied to the digital baseband signals, producing $R_{m}^{\prime}[n]$ which replaces $R_{m}[n]$ :

$$
R_{m}^{\prime}[n]=F\left[X_{m}[n]\right] e^{j 2 \pi f_{m} / f_{s}}
$$

\section{E. Class-S Transmitter Power Efficiency}

We review the operation and power efficiency of Class-S transmitters, which will allow analytical prediction on the 
average power efficiency of MDPC based digital transmitters by evaluating coding efficiency and peak PA efficiency. For a Class-S transmitter (Fig. 4b), which consists of a Class-D PA followed by an LC band-pass filter (BPF), following the definition on coding efficiency given in [11-13], we determine the coding efficiency as the in-band channel power divided by the total signal power both at the transmitter output. What makes it different from Class-D operation is the way the input signal is driving the PA; in order to modulate the output envelope amplitude, the input signal duty cycle is modulated.

First, let us consider the average power efficiency of the Class-S transmitter shown in Fig. $4 \mathrm{~b}$ with an ideal case where 1) the PA has an infinite bandwidth with a constant power efficiency and 2) the output filter has an infinite Q and allows only the fundamental component to pass through towards the load. The PA drain voltage for a square wave input signal with a frequency $\omega_{0}$ is also a square wave, which can be written in a Fourier series,

$$
V_{D}=\frac{V_{D D}}{2}\left[1+\frac{4}{\pi}\left(\sin \theta+\frac{1}{3} \sin 3 \theta+\frac{1}{5} \sin 5 \theta+\cdots\right)\right]
$$

where $V_{D D}$ is the supply voltage and $\theta=\omega_{0} t$. Since the BPF is assumed to pass only the fundamental component, the load voltage is given by

$$
V_{O}=\frac{2 V_{D D}}{\pi} \sin \theta
$$

Although only the fundamental component of the square-wave signal at the BPF input passes through and reaches the load, there is no energy loss since the BPF consists of ideal lossless reactive components. Because the BPF output does not contain high-order harmonics, following the definition of coding efficiency, we obtain $100 \%$ coding efficiency in this ideal case. The power delivered to the load is given by

$$
P_{L}=\frac{{\widehat{V_{O}}}^{2}}{2 R_{L}}=\frac{2 V_{D D}^{2}}{\pi^{2} R_{L}}
$$

where $\widehat{V_{O}}=2 V_{D D} / \pi$ is the peak output voltage applied to the load resistance $R_{L}$. The average current from the supply is obtained as

$$
\overline{I_{D C}}=\frac{1}{2 \pi} \int_{0}^{\pi} \frac{V_{O}}{R_{L}} d \theta=\frac{\widehat{V_{O}}}{\pi R_{L}}=\frac{2 V_{D D}}{\pi^{2} R_{L}} .
$$

The power delivered from the supply is determined as

$$
\overline{P_{D C}}=V_{D D} \overline{I_{D C}}=\frac{2 V_{D D}^{2}}{\pi^{2} R_{L}}
$$

The peak PA efficiency is obtained by dividing the power delivered to the load by the power delivered from the supply

$$
\eta_{P A}=\frac{P_{L}}{\overline{P_{D C}}}=100 \% .
$$

The average PA efficiency $\bar{\eta}$ is $100 \%$, which is obtained from

$$
\bar{\eta}=\eta_{P A} \eta_{c}
$$

where $\eta_{P A}$ is the peak PA efficiency and $\eta_{c}$ is the coding efficiency. If the PA input is modulated by oversampling such as delta-sigma modulation, although there are no high-order harmonics at the load, the BPF allows in-band quantization noise to pass; consequently coding efficiency drops, which decreases the PA average efficiency.

Second, let us consider the average power efficiency of the Class-S transmitter with a practical case where 1) the PA has a finite bandwidth with the peak power efficiency $\eta_{P A}$ only in the passband and 2) the output filter does not completely block high-order harmonics. In order to consider the impact of efficiency drop compared to the ideal case, an efficiency degradation factor $\alpha$ can be determined as

$$
\alpha=\frac{P_{O}}{P_{D C}}\left(\eta_{P A}\right)^{-1}=\frac{P_{L}+\sum_{i=2}^{\infty} P_{L}^{i}}{P_{L}+\sum_{i=2}^{\infty} P_{L}^{i}\left(\frac{\eta_{P A}}{\eta_{P A}^{i}}\right)}
$$

where $P_{O}$ is the total power including both the fundamental and high-order components at the BPF output, $P_{L}$ is the power delivered to the load for the fundamental component, and $P_{L}^{i}$ and $\eta_{P A}^{i}$ are the power delivered to the load and the PA efficiency for the $i$-th order harmonic component, respectively. Using the efficiency degradation factor $\alpha$, the average PA efficiency is obtained as

$$
\bar{\eta}=\eta_{e} \eta_{c}=\left(\alpha \eta_{P A}\right) \eta_{c}
$$

where $\eta_{e}$ denotes the effective PA efficiency considering the efficiency degradation. Suppose that the PA efficiency increasingly drops for a higher-order component. Then, as the PA bandwidth gets narrower, $\alpha$ decreases, which means that the effective PA power efficiency $\eta_{e}$ also decreases. Since the high-order harmonics at the load decreases as the PA bandwidth gets narrower, however, the coding efficiency $\eta_{c}$ may increase. Nevertheless, if the limited PA bandwidth prevents the drain voltage and current from achieving a zero-voltage switching condition, the PA peak efficiency $\eta_{P A}$ significantly drops, which in turn decreases the average power efficiency $\bar{\eta}$.

\section{Digital OUtPhasing TRAnSmitTER ARChitecture FOR NON-CONTIGUOUS CONCURRENT MULTI-BAND}

Fig. 5 shows the proposed concurrent multi-band digital outphasing transmitter architecture with 2-dimensional power coding. The multiple quadrature baseband signals are up-converted to each band (component carrier in CA) in digital domain. Multiband multi-bit BPDSM combines the high-resolution digital baseband inputs ( $>10$ bits) into a single-stream multi-level digital signal (e.g. 7 levels) with high linearity. Because the implementation complexity of Class-S digital PAs is increasingly difficult with a large number of 


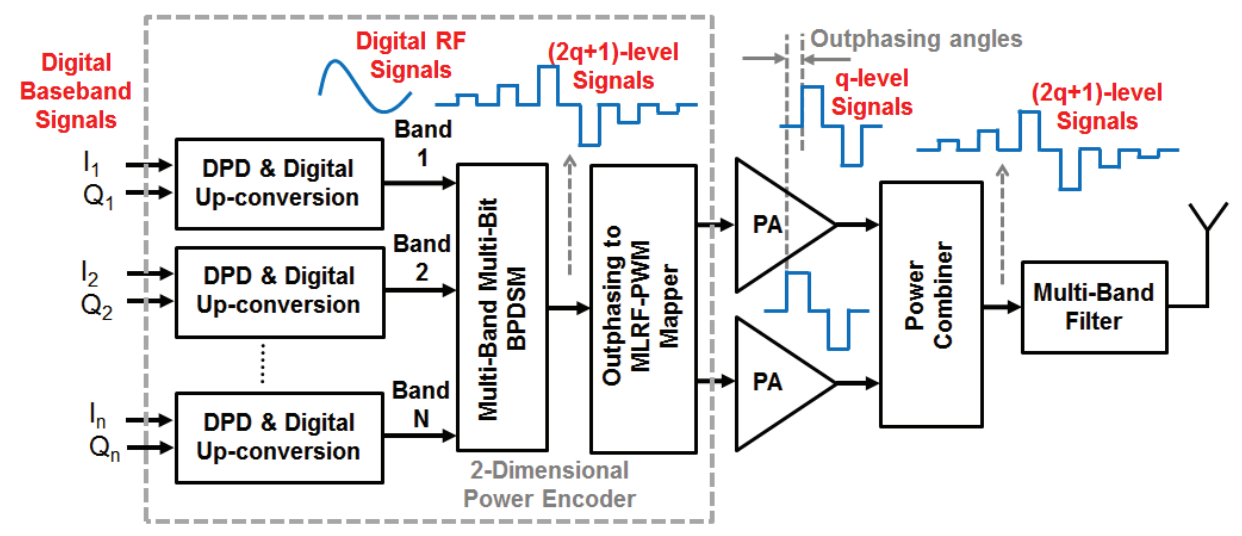

Fig. 5. Proposed digital outphasing transmitter architecture with 2-dimensional power coding.

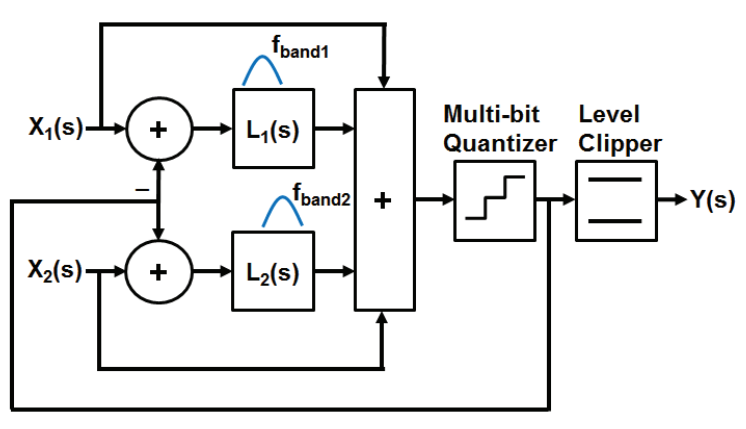

Fig. 6. Multi-band band-pass delta-sigma modulator (BPDSM) with level clipping for high coding efficiency.

output levels ( $>5$ levels), the single-stream multi-level BPDSM output signal is transformed into dual-stream multi-level (e.g. 3 levels) PWM signals that are outphased to each other, so that the PAs can produce only a small number of output levels. By keeping the outphasing angles small, non-isolated Chireix power combiners can be used with a very high efficiency in summing the output power of the two PAs. Therefore, both high efficiency and high linearity can be obtained with low sensitivity to mismatch.

The digital outphasing transmitter uses oversampling BPDSM, which reduces the digital RF signal resolution (as discussed in Section II) and also differentiate the digital outphasing transmitter from the conventional outphasing transmitters. Outphasing transmitter with discrete PWM [29] improves the transmitter power efficiency by combining outphasing and PWM, but the outphasing requires very fine resolution. High-fidelity analog/RF front-end, therefore, is required. Outphasing transmitter with envelope PWM [30] also requires very fine outphasing resolution. Furthermore, envelope PWM needs more than 100 times higher sampling rate than the largest frequency difference among multiband carriers.

\section{A. Multi-Band Multi-Bit BPDSM with Level Clipping}

Fig. 6 shows the multi-band multi-bit BPDSM with level clipping for high power coding efficiency, which is used in the proposed transmitter architecture. Two digital loop-filters $\mathrm{L}_{1}(\mathrm{~s})$ and $L_{2}(s)$ have a different resonant frequency tuned for each carrier frequency. The dual-band input signal $\mathrm{X}_{1}(\mathrm{~s})$ and $\mathrm{X}_{2}(\mathrm{~s})$ are scaled such that the quantizer is not saturated in order to maintain the BPDSM feedback stability and linearity. Triple-band input can be applied by adding a third loop-filter $\mathrm{L}_{3}(\mathrm{~s})$ at the expense of reduced modulator feedback stability.

Design guidelines on the multiband BPDSM can be obtained by observing its noise and signal transfer functions. For a general multi-band BPDSM with the modulator architecture in Fig. 6, the modulator output is related to the input signals by one noise transfer function and multiple signal transfer function:

$$
Y(z)=\operatorname{NTF}(z) E(z)+\sum_{i=1}^{M} S T F_{i}(z) X(z)
$$

where $E(z)$ represents the quantization noise. The noise transfer function is derived in [4] as

$$
\operatorname{NTF}(z)=\left(1+\sum_{i=1}^{M} L_{i}(z)\right)^{-1}
$$

while the signal transfer functions are given by

$$
\operatorname{STF}_{i}(z)=\left(1+L_{i}(z)\right) /\left(1+\sum_{i=1}^{M} L_{i}(z)\right)
$$

The noise transfer function shows that, to avoid noise peaking in the BPDSM output spectrum, we should not choose the same zeroes for all digital loop filters. The signal transfer function shows that the multiple carrier frequencies, to reduce the insertion loss in the signal band, should be far away from each other. Following these two guidelines, we design a multiband BPDSM in three steps. First, design each loop filter for a single-band BPDSM [31]. Second, adjust the zeroes in the digital loop filters such that they are away from each other until there is no large noise peaking. Third, if the in-band insertion loss is high, increase the order of the digital loop filter order.

The level clipper reduces the number of BPDSM output levels, which improves the coding efficiency at the expense of linearity and out-of-band emission. Lower than $-50-\mathrm{dBc}$ 


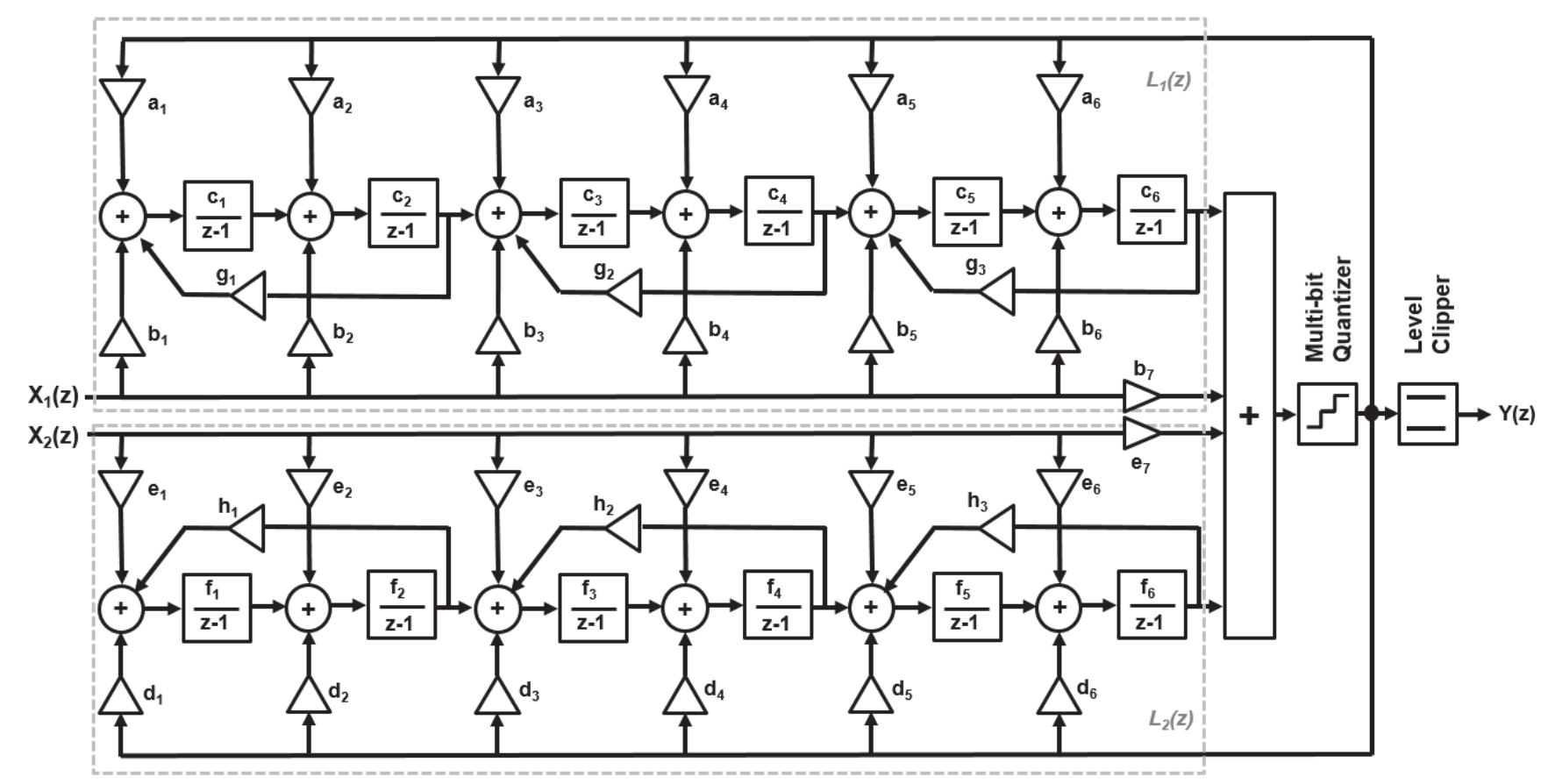

Fig. 7. Dual-band BPDSM implementation with two 6-order loop filters.

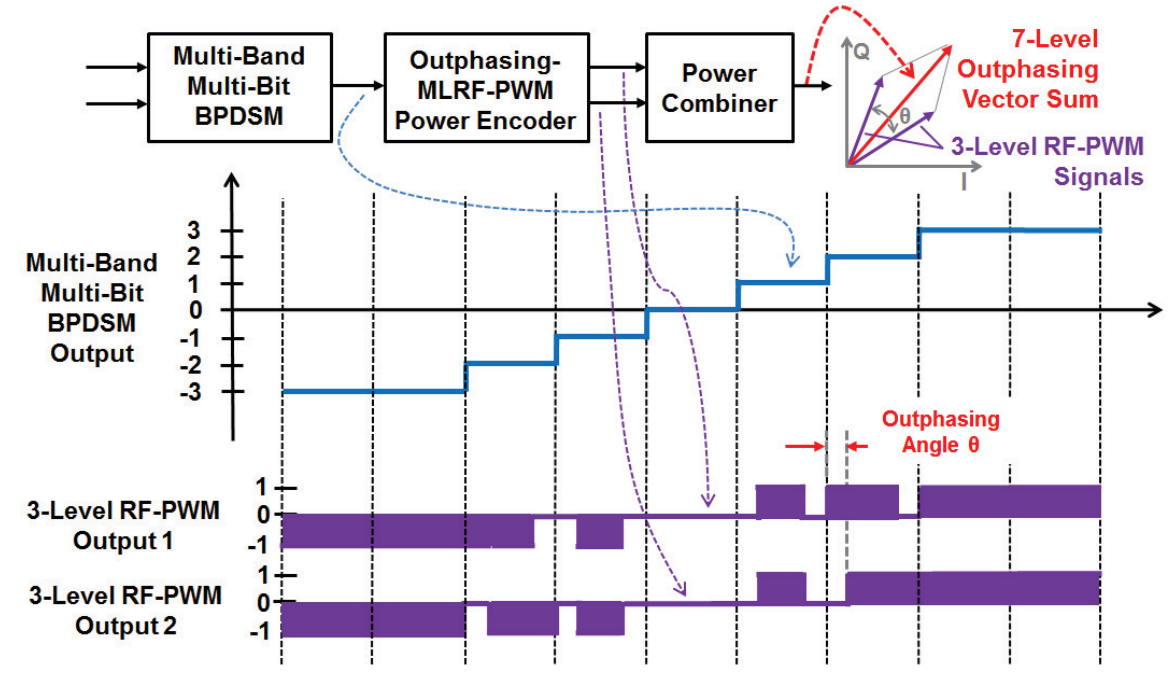

Fig. 8. Power encoder operation for outphasing two 3-level RF PWM signals that are mapped from a 7-level BPDSM signal.

out-of-band emissions can be achieved with a 9-level quantizer without clipping. Simulation results show that clipping the 9-level quantizer output signals into 7-level improves the coding efficiency by more than $10 \%$ with acceptable EVM performance and out-of-band emissions for dual-band LTE signals with $10-\mathrm{MHz}+20-\mathrm{MHz}$ bandwidth.

Fig. 7 shows a dual-band BPDSM design with two 6-th order loop filters, a 9-level quantizer shared by the two loop filters, and a 7-level clipper for a concurrent dual-band LTE transmitter prototype. Each loop filter consists of a three-stage cascade of resonators with distributed feedback (CRFB) whose analysis and design have been extensively studied in many literature including [5], [31]. In hardware implementation, carrier frequencies can be reconfigured by updating the digital loop filter coefficients with a set of pre-calculated values. Since the signal path up to the PA inputs is all in digital domain, a wide frequency range can be supported.

\section{B. Outphasing Multi-level RF Pulse-Width Modulation (ML-RFPWM) Power Encoder}

Fig. 8 shows an example operation of the two-dimensional power encoder, which transforms the single-stream 7-level BPDSM output signals into dual-stream 3-level PWM outphasing MLRF-PWM signals. Discrete outphasing is applied to each pulse, so that the power combiner can recover the original 7-level BPDSM output signals. The number of 
TABLE I

MDPC SCHEME 1, WHICH ENCODES A 5-LEVEL BPDSM SIGNAL INTO OUTPHASING 2-LEVEL RFPWM SIGNALS

\begin{tabular}{|c|c|c|}
\hline $\begin{array}{c}\text { BPDSM } \\
\text { signal level }\end{array}$ & $\begin{array}{c}\text { 2-level } \\
\text { RFPWM } \\
\text { signal 1 }\end{array}$ & $\begin{array}{c}\text { 2-level } \\
\text { RFPWM } \\
\text { signal 2 }\end{array}$ \\
\hline 2 & $1,1,1,1$ & $1,1,1,1$ \\
\hline 1 & $1,1,1,-1$ & $-1,1,1,1$ \\
\hline 0 & $-1,-1,1,1$ & $1,1,-1,-1$ \\
\hline-1 & $-1,-1,-1,1$ & $1,-1,-1,-1$ \\
\hline-2 & $-1,-1,-1,-1$ & $-1,-1,-1,-1$ \\
\hline
\end{tabular}

TABLE II

MDPC SCHEME 2, WHICH ENCODES A 7-LEVEL BPDSM SIGNAL INTO OUTPHASING 3-LEVEL RFPWM SIGNALS

\begin{tabular}{|c|c|c|}
\hline $\begin{array}{c}\text { BPDSM } \\
\text { signal level }\end{array}$ & $\begin{array}{c}\text { 3-level } \\
\text { RFPWM } \\
\text { signal 1 }\end{array}$ & $\begin{array}{c}\text { 3-level } \\
\text { RFPWM } \\
\text { signal 2 }\end{array}$ \\
\hline 3 & $1,1,1,1$ & $1,1,1,1$ \\
\hline 2 & $0,1,1,1$ & $1,1,1,0$ \\
\hline 1 & $1,1,0,0$ & $0,0,1,1$ \\
\hline 0 & $0,0,0,0$ & $0,0,0,0$ \\
\hline-1 & $-1,-1,0,0$ & $0,0,-1,-1$ \\
\hline-2 & $0,-1,-1,-1$ & $-1,-1,-1,0$ \\
\hline-3 & $-1,-1,-1,-1$ & $-1,-1,-1,-1$ \\
\hline
\end{tabular}

output levels can be determined depending on performance requirements on linearity and out-of-band emission.

The sampling rate of the power encoder determines the minimum outphasing angles. A higher sampling rate allows smaller minimum outphasing angles, so that a larger number of BPDSM output levels can be transformed into MLRF-PWM signals with the same number of output levels.

For high coding efficiency, the duty cycles of the ML-RFPWM signals are maintained higher than $12.5 \%$ of the carrier with the highest frequency among multiple aggregated bands. Although allowing a lower duty cycle allows a larger number of BPDSM output levels, the power coding efficiency degrades as the duty cycle variation grows.

To illustrate nonlinear MDPC schemes, which encode a BPDSM signal into outphasing ML-RFPWM signals, 5-level and 7-level BPDSM signals are generated from a concurrent dual-band LTE signal with $40-\mathrm{MHz}$ aggregate bandwidth at $856-\mathrm{MHz}$ and $1450-\mathrm{MHz}$ frequency bands. Table I and II show the two difference MDPC schemes that are used to encode the two BPDSM signals. The 5-level BPDSM signal is encoded into outphasing 2-level bipolar RFPWM signals. The 7-level BPDSM signal is encoded into outphasing 3-level RFPWM signals. Each BPDSM symbol is translated into 4 RFPWM codes. DPD is not applied to the baseband signals to compare the nonlinearity of the two MDPC schemes. Table III summarizes the adjacent channel leakage power (ACPR) and coding efficiency of these simulated concurrent dual-band LTE signals.

Fig. 9 shows the spectrum of the 5-level and 7-level BPDSM signals. 7-level BPDSM signal shows lower quantization noise from delta-sigma modulation. However, Fig. 10(a) shows that

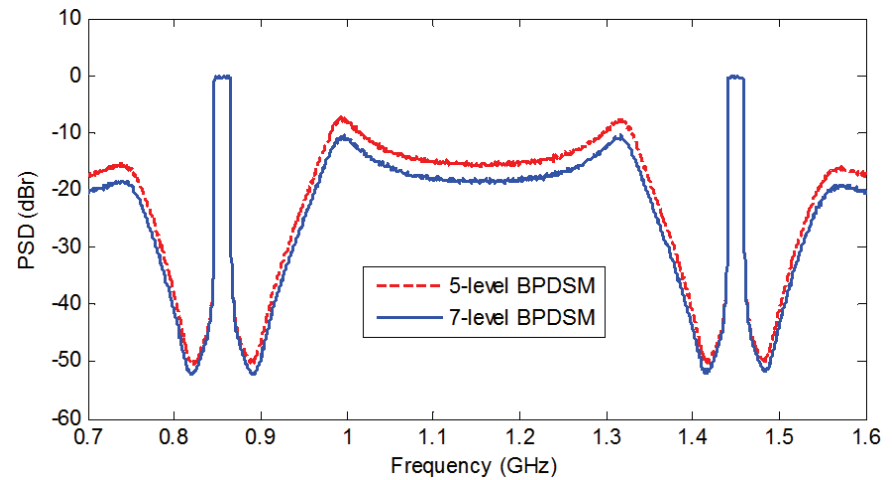

Fig. 9. Simulated dual-band BPDSM output for LTE signals with $40-\mathrm{MHz}$ aggregate bandwidth at $856-\mathrm{MHz}$ and $1450-\mathrm{MHz}$ bands.

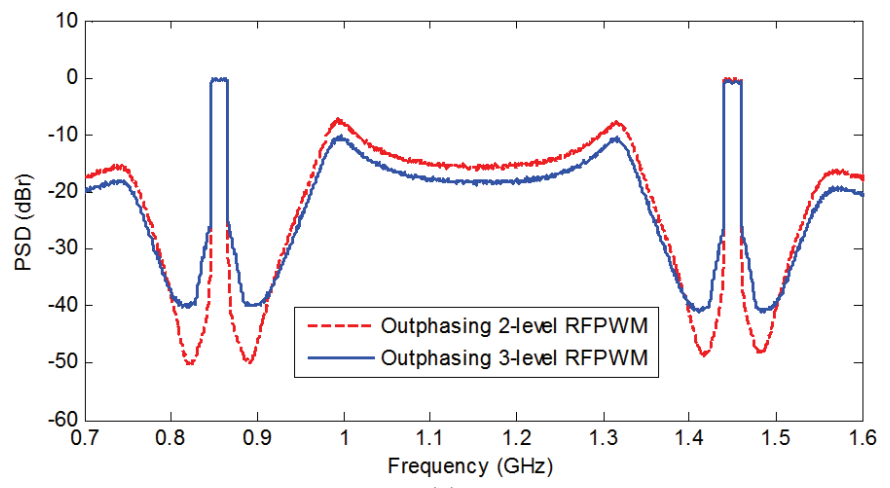

(a)

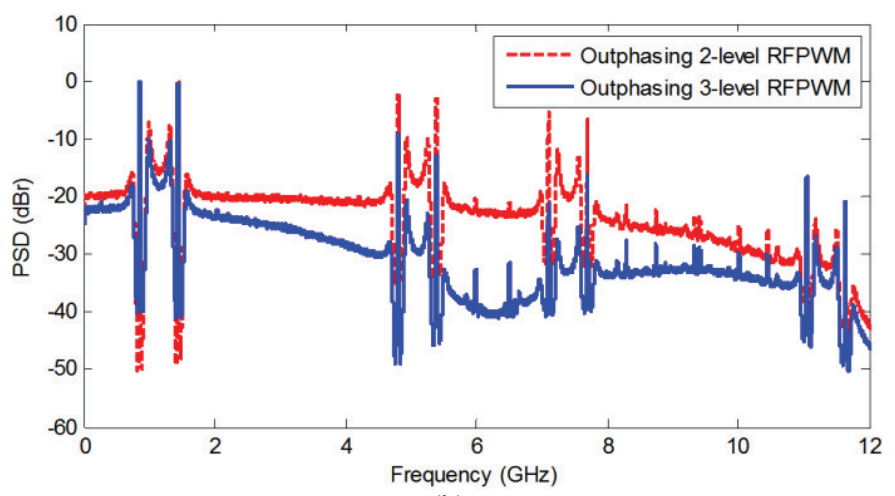

(b)

Fig. 10. Simulated concurrent dual-band transmission of LTE signals with $40-\mathrm{MHz}$ aggregate bandwidth at $856-\mathrm{MHz}$ and $1450-\mathrm{MHz}$ bands using the two MDPC schemes, which transform 5- and 7-level BPDSM output signals into outphasing 2- and 3-level RFPWM signals, respectively (a) close-in spectrum, (b) wideband spectrum.

the outphasing 2-level RFPWM signals, which is encoded by MDPC scheme 1 (Table I) show a lower sideband spectrum leakage near the two in-band channels at both $856 \mathrm{MHz}$ and $1450 \mathrm{MHz}$. This shows that MDPC scheme 1 is more linear than the MDPC scheme 2. The undesirable sideband spectrum regrowth with the MDPC scheme 2 can be suppressed by DPD on baseband signals.

Concerning on coding efficiency, both Fig. 10(a) and Fig. 10(b) show that the outphasing 3-level RFPWM signals have 
TABLE III

ACPR AND CODING EFFICIENCY OF THE SiMUlated CONCURRENT DuAL-BAND LTE Signals with 40-MHz AgGREgATE BANDWIDTH

\begin{tabular}{|l|r|r|r|}
\hline & $\begin{array}{r}\text { ACPR } \\
856-\mathrm{MHz} \\
\text { Band }\end{array}$ & $\begin{array}{r}\text { ACPR } \\
1450-\mathrm{MHz} \\
\text { Band }\end{array}$ & $\begin{array}{r}\text { Coding } \\
\text { Efficiency }\end{array}$ \\
\hline $\begin{array}{l}\text { 5-level } \\
\text { BPDSM }\end{array}$ & $-49.9 \mathrm{dBc}$ & $-50.0 \mathrm{dBc}$ & $42.2 \%$ \\
\hline $\begin{array}{l}\text { 7-level } \\
\text { BPDSM }\end{array}$ & $-49.0 \mathrm{dBc}$ & $-49.1 \mathrm{dBc}$ & $59.1 \%$ \\
\hline $\begin{array}{l}\text { 2-level } \\
\text { RFPWM }\end{array}$ & $-49.6 \mathrm{dBc}$ & $-49.0 \mathrm{dBc}$ & $21.5 \%$ \\
\hline $\begin{array}{l}\text { 3-level } \\
\text { RFPWM }\end{array}$ & $-40.6 \mathrm{dBc}$ & $-41.4 \mathrm{dBc}$ & $50.1 \%$ \\
\hline
\end{tabular}

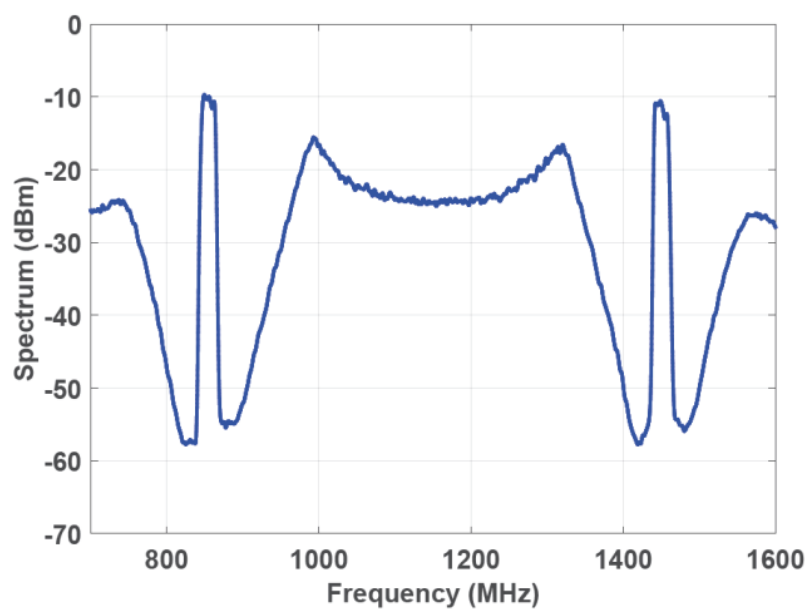

Fig. 11. Measured concurrent dual-band LTE signal transmission using the MDPC scheme 1 (Table I) using a Chireix power combiner with $1-\mathrm{dB}$ bandwidth from DC to $1.8 \mathrm{GHz}$.

lower out-of-band emission. Therefore, the MDPC scheme 2 provides a higher coding efficiency of $50.1 \%$ compared to the MDPC scheme 1 with $21.5 \%$ coding efficiency. The average transmitter power efficiency difference between the two coding schemes is larger than the difference in the coding efficiency. The average power efficiency considers power loss from outphasing. To produce transmitter output envelope with zero amplitude, the MDPC scheme 1 with 2-level RFPWM output code cancels out the output power from the two PAs. The MDPC scheme 2 with 3-level RFPWM output code, however, does not need to cancel the PA output power to produce zero envelope amplitude, attributing to a higher coding efficiency.

The outphasing angle of two PAs to transmit the two RFPWM signals depends on the sequence of power codes. For example, with the MDPC scheme 1, for the BPDSM signal level \pm 2 , the two power codes are same and so the PA outphasing angle is zero. When the two BPDSM signal level \pm 1 are repeating, since the repeating power codes have a $90^{\circ}$ phase offset, the two PA outphasing angle becomes $45^{\circ}$. Although the zero BPDSM signal level corresponds to the maximum outphasing angle of $90^{\circ}$, by turning off both two PAs, no power consumption is necessary, avoiding efficiency degradation. Consequently, the MDPC scheme 1 needs no more than $45^{\circ}$ outphasing angles, which significantly improves the average

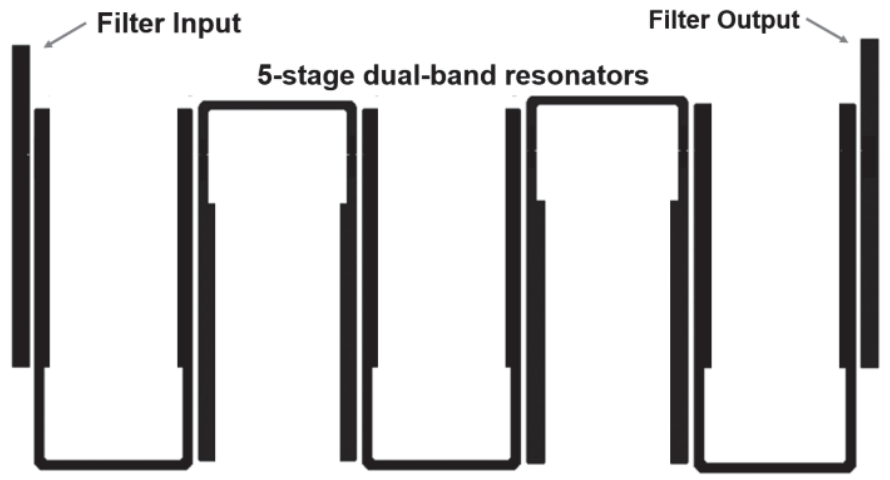

Fig. 12. Dual-band RF filter designed with Rogers RO4350 substrate in order to suppress the out-of-band noise with the concurrent dual-band LTE signal transmission at $856 \mathrm{MHz}$ and $1450 \mathrm{MHz}$ (EM simulation shows less than $1.5-\mathrm{dB}$ insertion loss).

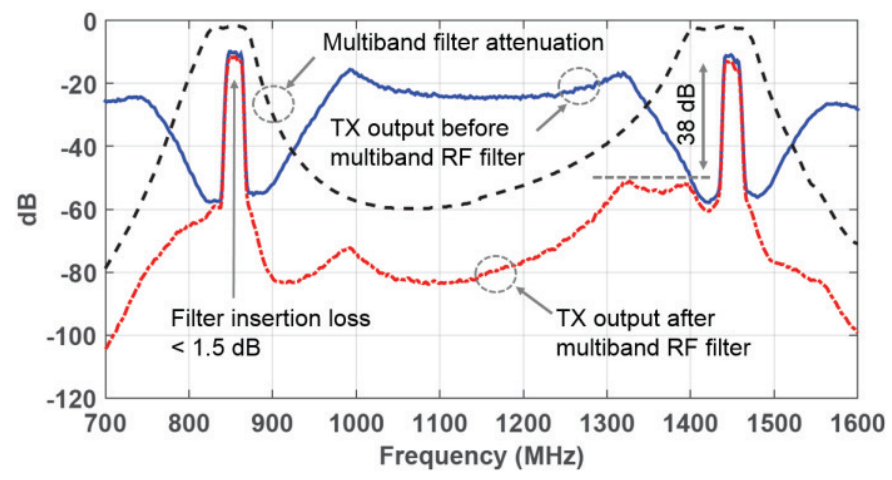

Fig. 13. Attenuation of the out-of-band noise with the concurrent dual-band transmission by using a multiband RF filter. The filter output is obtained by combining the measured transmit spectrum with the simulated filter $\mathrm{S}_{21}$.

power efficiency compared to the conventional outphasing transmitters.

Fig. 11 shows the measured concurrent dual-band LTE signal transmission using the MDPC scheme 1 (Table I) with a limited power combiner bandwidth. A 25-GSPS arbitrary signal generator Tektronics AWG70000 and wideband driver amplifier Hittite HMC870LC5 with 20-GHz bandwidth was used with a custom designed Chireix power combiner with a 1-dB bandwidth from DC to $1.8 \mathrm{GHz}$. Compared to the simulation result shown in Fig. 10(a), approximately up to 6-dB degradation in ACPR is observed, which is sufficient to meet LTE transmit spectrum.

\section{Multiband RF Filter}

Proposed digital outphasing transmitter requires two filtering functions in order to suppress excessive out-of-band noise, which is a common problem with digital transmitters exploiting oversampling delta-sigma modulation.

First, in order to meet a given transmit spectral emission mask and ACPR requirements, a high-order multiband RF filter whose passbands include the multiple transmit channels. We designed a microstrip based RF filter using a Rogers RO4350 substrate (Fig. 12). The filter consists of a 5-stage cascade of a dual resonator reported in [39]. 2.5D EM simulation results on 


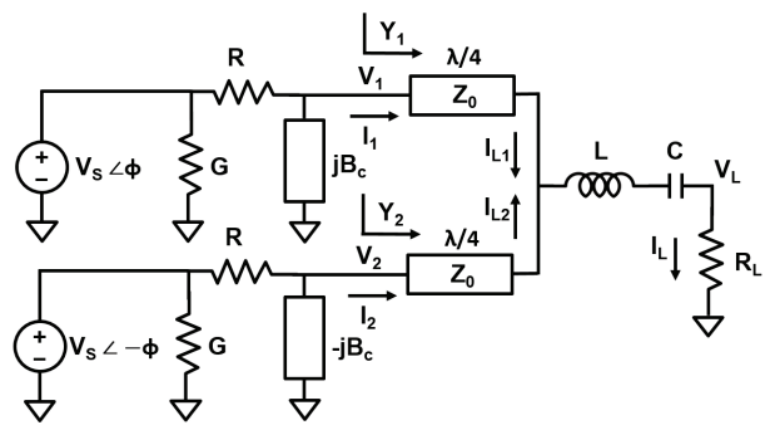

Fig. 14. Large-signal outphasing Class-D PA model with a Chireix power combiner, considering finite switch-on resistance by the resistance $R$ and off-state leakage current by the conductance $G$.

the physical layout indicates that insertion loss at $857 \mathrm{MHz}$ and $1450 \mathrm{MHz}$ will be less than $1.5 \mathrm{~dB}$. Fig. 13 shows the simulated filter output with the input signal as the measured dual-band LTE transmission. The number of filter stages control the trade-off between the residual out-of-band noise and in-band insertion loss.

Second, the higher order spectral replicas of the digital transmitters should be suppressed by additional low-pass filtering. Particularly, if the multiband RF filter is based on a transmission line structure, the suppression on the higher-order harmonics are not enough to satisfy receiver band noise requirements. Since the digital sampling rate of the proposed transmitter is at least in the order of $5-10 \mathrm{GHz}$, this low-pass filtering is often available for free from the duplexer in frequency-domain division (FDD) systems. Although time-domain division (TDD) systems may need a separate low-pass filter, the wide distance between the spectral replicas due to a high digital sampling rate makes the low-pass filter design with much less complexity compared to the multiband RF filter. For example, if the in-band channels are below 2 $\mathrm{GHz}$, a typical low-pass filter with a less than 1-dB insertion loss will provide more than $60-\mathrm{dB}$ attenuation on the high-frequency digital images when the images are separated by $2-3 \mathrm{GHz}$.

\section{Efficiency of a Class-S Digital Outphasing Transmitter}

The power efficiency of the proposed digital outphasing transmitter with Class-S operation is related to coding efficiency and the PA power efficiency, which constructs the outphasing transmitter, as well as power combining efficiency. Although ideal Class-D outphasing PAs provide 100\% efficiency, non-ideal switch characteristics of transistors degrades the power efficiency. The existing analysis works on Chireix power combiner [26], [33], [34] do not consider these non-idealities at the same time.

Therefore to evaluate the impact of the transistor non-idealities on the power efficiency of the proposed digital outphasing technique, we present an efficiency analysis on outphasing Class-D PAs driven by 2-level bipolar RFPWM signals. We consider two non-idealities of finite switch turn-on resistance and off-state leakage current. The finite turn-on resistance will vary the Class-D PA efficiency under load modulation while the off-state leakage current will eventually

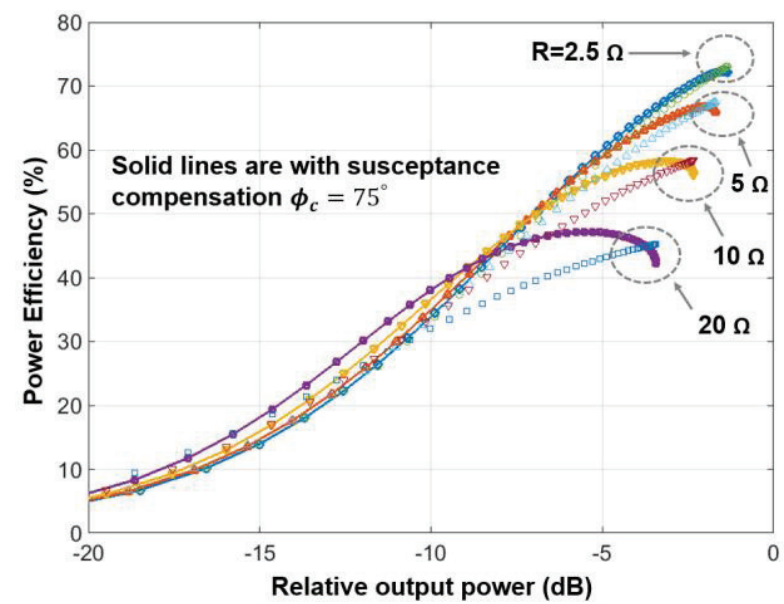

Fig. 15. Chireix outphasing power efficiency with Class-D PAs considering finite switch-on resistance $R$ and off-state leakage current. Solid lines with susceptance compensation shows high efficiency but the improvement gets smaller if the switch-on resistance is small, which makes the Class-D PA close to an ideal voltage source.

decrease the PA efficiency towards zero as the power combiner output is small enough to be comparable with the off-state leakage current.

Fig. 14 shows a large-signal model for a simplified digital outphasing transmitter with Class-S operation, which consists of two Class-D PAs whose output power is summed by a Chireix power combiner for high efficiency. Chireix power combiners provide varying load impedance to each Class-D PA depending on outphasing angles between the two PAs. To evaluate the power efficiency degradation by transistor non-idealities, the source resistance $R$ in the large signal model in Fig. 14 represents the lumped impact of the finite switch turn-on resistance. The shunt conductance $G$ represents the lumped impact of the off-state leakage current. An ideal output filter is assumed, which only allows the fundamental component to pass; the power efficiency and the output power in the following analysis do not include high-order harmonics.

From the analysis on the schematic circuit model in Fig. 14, we obtain the admittance seen by the Class-D PAs, which coincides with the previous works [26], [34]

$$
Y_{1 / 2}=G_{0} \mp j\left(B_{0} \pm B_{c}\right)=G_{0} \mp j B
$$

with $G_{0}=\left(R_{L} / Z_{0}^{2}\right) 2 \cos ^{2} \phi$ and $B_{0}=\left(R_{L} / Z_{0}^{2}\right) \sin 2 \phi$. The compensation susceptance can be chosen as

$$
B_{c}=\left(R_{L} / Z_{0}^{2}\right) \sin 2 \phi_{c}
$$

such that the compensation angle $\phi_{c}$ maximizes the average power efficiency for a given modulated transmit signal.

Since resistive elements do not alter phase, the PA output node voltages $V_{l}$ and $V_{2}$ can be written in a phasor form as

$$
V_{1 / 2}=V_{0} e^{ \pm j \phi}
$$

with the same phase as the voltage sources where $V_{0}$ is a constant. 
Then we find the power delivered to the load $R_{L}$ as

$$
P_{L}=\frac{1}{2}\left|V_{0}\right|^{2} \operatorname{Re}\left\{Y_{1}\right\}+\frac{1}{2}\left|V_{0}\right|^{2} \operatorname{Re}\left\{Y_{2}\right\}=\left|V_{0}\right|^{2} G_{0}
$$

and we obtain the DC power delivered by the voltage sources in the same way as

$$
\begin{aligned}
P_{D C}=\left|V_{0}\right|^{2}\left[G_{0}+\right. & R\left(G_{0}^{2}+B^{2}\right) \\
& \left.+G\left(\left(1+R G_{0}\right)^{2}+R^{2} B^{2}\right)\right]
\end{aligned}
$$

where the second term $\left|V_{0}\right|^{2} R\left(G_{0}^{2}+B^{2}\right)$ represents the extra power consumption due to the finite turn-on resistance while the third term $\left|V_{0}\right|^{2} G\left(\left(1+R G_{0}\right)^{2}+R^{2} B^{2}\right)$ shows the additional power consumption by the off-state leakage. Consequently the power efficiency is written as

$$
\begin{aligned}
\eta & =\frac{P_{L}}{P_{D C}} \\
& =\frac{G_{0}}{G_{0}+R\left(G_{0}^{2}+B^{2}\right)+G\left(\left(1+R G_{0}\right)^{2}+R^{2} B^{2}\right)} .
\end{aligned}
$$

Power back-off $P_{B}$ for a given outphasing angle $\phi$ is obtained by comparing the output power $P_{L}$ with the maximum output power when the outphasing angle is zero

$$
\begin{aligned}
P_{B} & =\frac{P_{L}}{P_{m}} \\
& =\frac{G_{0}}{G_{m}+R\left(G_{m}^{2}+B_{m}^{2}\right)+G\left(\left(1+R G_{m}\right)^{2}+R^{2} B_{m}^{2}\right)}
\end{aligned}
$$

where $G_{m}=2 R_{L} / Z_{0}^{2}$ and $B_{m}=-\left(R_{L} / Z_{0}^{2}\right) \sin 2 \phi_{c}$.

Fig. 15 shows the power efficiency $\eta$ and the output power back-off $P_{B}$ of an outphasing Class-S transmitter using non-ideal Class-D PAs with a leakage conductance of $7.4 \mathrm{mS}$ and a finite turn-on resistance of $2.5 \Omega, 5 \Omega, 10 \Omega$, and $20 \Omega$. A susceptance compensation angle of $75^{\circ}$ is applied. The zero power back-off point refers to an ideal case when all source power is delivered to the load. The advantage of using Class-D PAs with Chireix output phasing is that the Class-D PA is insensitive to load modulation, which is shown in Fig. 15 with a trend that the impact of susceptance compensation becomes small for a low turn-on resistance $R$. Comparison with measured results will be discussed with a prototype transmitter in Section IV.

The average efficiency $\bar{\eta}$ of a Class-S outphasing transmitter with Class-D PAs for a modulated signal is obtained by considering the output power and efficiency for each power code that it transmits,

$$
\bar{\eta}=\eta_{c}\left(1-L_{c}\right) \frac{\sum_{i} P_{L}\left(\phi_{i}\right)}{\sum_{i} P_{L}\left(\phi_{i}\right) / \eta\left(\phi_{i}\right)}
$$

where $\phi_{i}$ is an outphasing angle associated per power code, $L_{c}$ is power combiner insertion loss, and $\eta_{c}$ is the average coding efficiency, which is defined in [11]-[13], [37] as a ratio of the amount of the transmit power in the band of interests to the total transmit power. As discussed in Section II-E, in order to

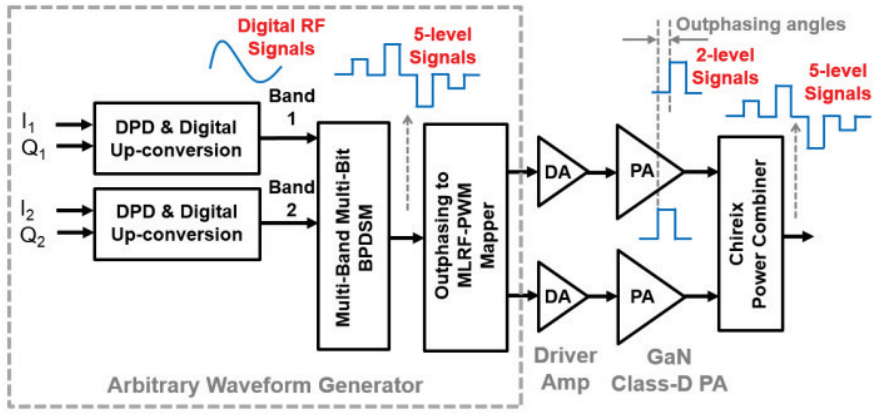

(a)

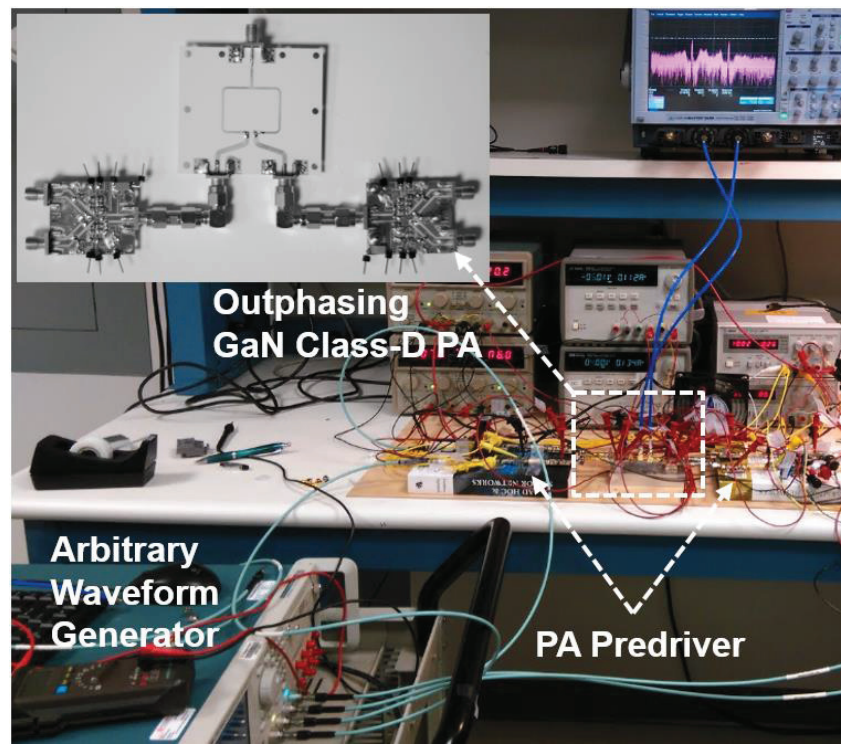

(b)

Fig. 16. Prototype digital outphasing transmitter using $1-\mathrm{GHz}$ bandwidth GaN Class-D PAs and a Chireix power combiner with a 1-dB bandwidth of 1.8-GHz (a) simplified block diagram, (b) photograph of the experimental setup for the prototype transmitter.

include the efficiency degradation due to the high-order harmonics, the power efficiency for each power code $\eta\left(\phi_{i}\right)$ should include the efficiency degradation factor $\alpha$ in Eq. (13). The derivation of the average power efficiency as well as the output power is in parallel with the power efficiency calculation of a PA with a multi-level supply [41].

The average transmit output power $\overline{P_{L}}$ in the bands of interests is obtained as

$$
\overline{P_{L}}=\eta_{c}\left(1-L_{c}\right) \sum_{i} P_{L}\left(\phi_{i}\right)
$$

Unless PAs have infinite bandwidth, the coding efficiency $\eta_{c}$ also depends on the PA characteristics as well as the statistical property of the power codes in transmission.

\section{PRototype Concurrent DuAL-BANd Digital OUTPHASING TRANSMITTER WITH GAN CLASS-D PA}

Fig. 16(a) shows the simplified block diagram of a digital Class-S outphasing transmitter using two Class-D PAs in 


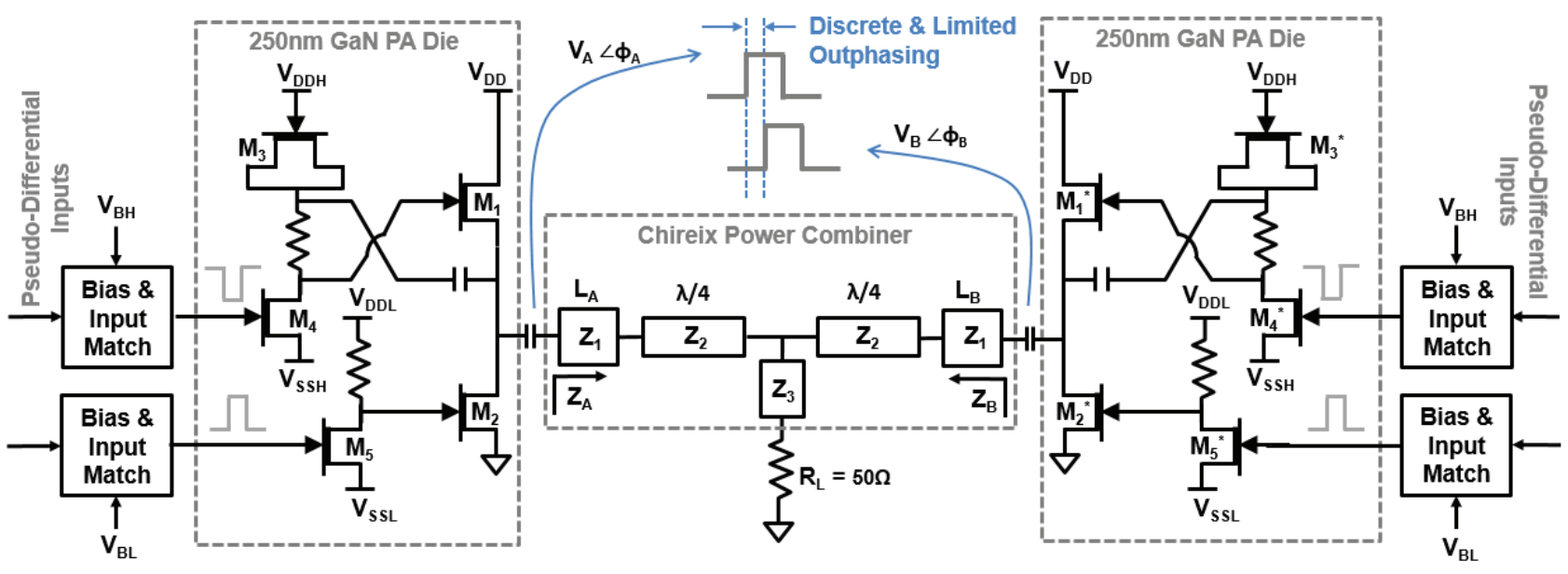

Fig. 17. Class-S digital outphasing transmitter circuit schematic, which consists of two GaN Class-D PAs and a Chireix power combiner. The susceptance adjustment for the Chireix power combiner is realized by the difference in the transmission line length between $\mathrm{L}_{\mathrm{A}}$ and $\mathrm{L}_{\mathrm{B}}$ [36].

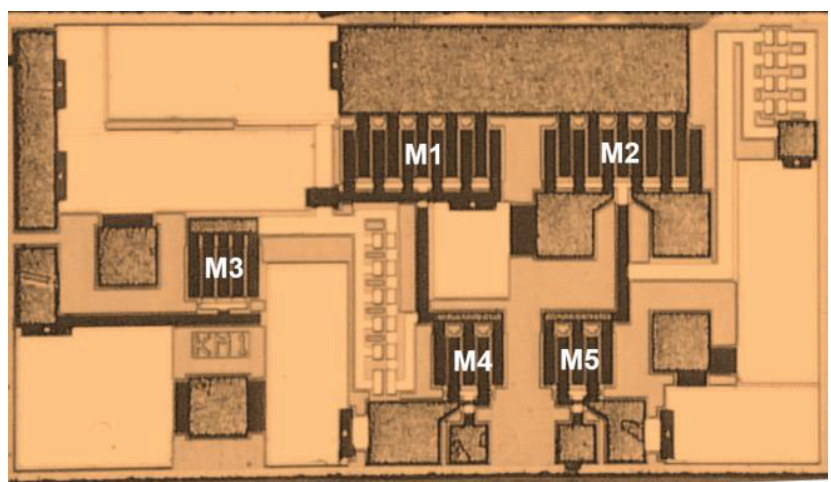

Fig. 18. Die photograph of the $250 \mathrm{~nm}$ GaN Class-D power amplifier (size $1.6 \mathrm{~mm} \times 0.9 \mathrm{~mm}$ ) [40].

Mitsubishi 0.25 um GaN technology. The outputs from the two $\mathrm{GaN}$ PAs are summed by a custom-designed Chireix power combiner shown in Fig. 16(b). A concurrent dual-band LTE signal is encoded into outphasing 2-level RFPWM signals using the MDPC scheme 1 (Table I) and downloaded into Tektronics AWG70000. The GaN Class-D PAs have a 3-dB bandwidth of 1-GHz. Each GaN Class-D PA has two internal pre-driver stages that are driven by two Hittite HMC870 driver amplifiers. Considering the 1-GHz bandwidth of the GaN PAs, $240-\mathrm{MHz}$ and $500-\mathrm{MHz}$ carriers are chosen. LTE signal with $15-\mathrm{MHz}$ aggregate channel bandwidth is transmitted, which have a very high PAPR of $11.7 \mathrm{~dB}$ at the high-band and $11.0 \mathrm{~dB}$ at the low-band. 2.15-GHz BPDSM sampling clock rate is chosen as approximately 4 times higher than the highest carrier frequency of $500 \mathrm{MHz}$. To simplify implementation, we used a MDPC encoder sampling clock frequency of $8.6 \mathrm{GHz}$, which is again 4 times higher than the BPDSM sampling clock rate. By using an open-loop phase modulator, such as reported in [41], the same 2.15-GHz sampling clock can be used with the MDPC encoder in our prototype.

\section{A. GaN Class-D Power Amplifier}

Fig. 17 shows the circuit schematic of the GaN Class-D PAs with the Chireix power combiner. The GaN Class-D PA (Fig.

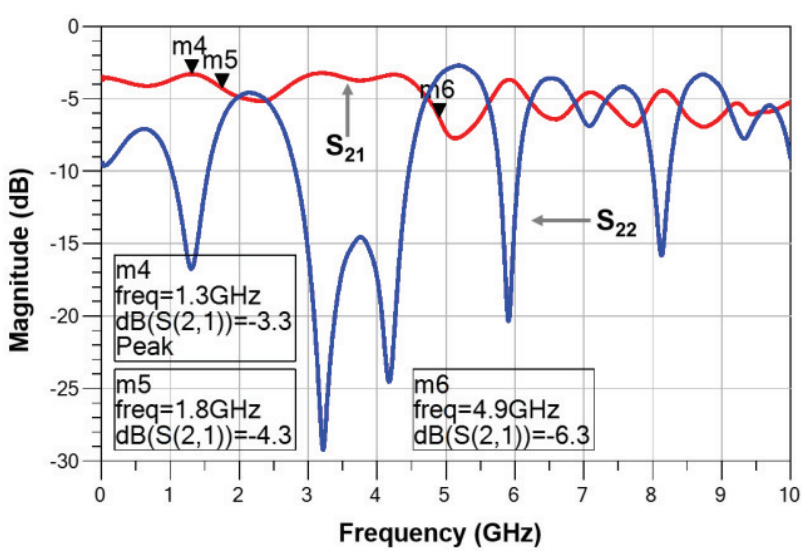

Fig. 19. Measured output port return loss $S_{22}$ and combining gain $S_{21}$ of the Chireix power combiner.

18) is implemented using n-type depletion HEMTs only, based on the design from [40] in order to achieve a high PAE. Without p-type transistors, the gate-driver for the main pull-up n-type transistor M1 needs to draw a large current in order to fully turn off $\mathrm{M} 1$. The capacitor $\mathrm{C}_{\mathrm{B}}$, which is pre-charged to $V_{D D H}$ when $\mathrm{M} 2$ is on and the output voltage is low. In the very next cycle, the output voltage goes high, which helps to turn on $\mathrm{M} 2$ through the pre-charged capacitor $\mathrm{C}_{\mathrm{B}}$. As the output voltage goes up, $\mathrm{C}_{\mathrm{B}}$ increases the $\mathrm{M} 3$ source voltage higher than $V_{D D H}$ so that M1 turns on without drawing a large current from $V_{D D H}$ by making M3 off. The output port of the combiner has 50-ohm characteristic impedance while the two input ports have 35-ohm characteristic impedance, which is matched to the output of the GaN Class-D PAs. Fig. 19 shows that the combiner 1-dB bandwidth is from DC to $1.8 \mathrm{GHz}$ while the 3-dB bandwidth is up to $4.9 \mathrm{GHz}$.

Fig. 20 shows the output power, drain efficiency (DE), and power added efficiency (PAE) of the GaN Class-D PA while the supply voltage sweeps between $15 \mathrm{~V}$ and $35 \mathrm{~V}$. 77\% peak $\mathrm{DE}$ and $67 \%$ peak PAE are achieved with $35.2-\mathrm{dBm}$ output to a 50-ohm load. If an ideal Class-B PA is used to transmit the dual-band LTE test signal, the overall PAPR of the dual-band 


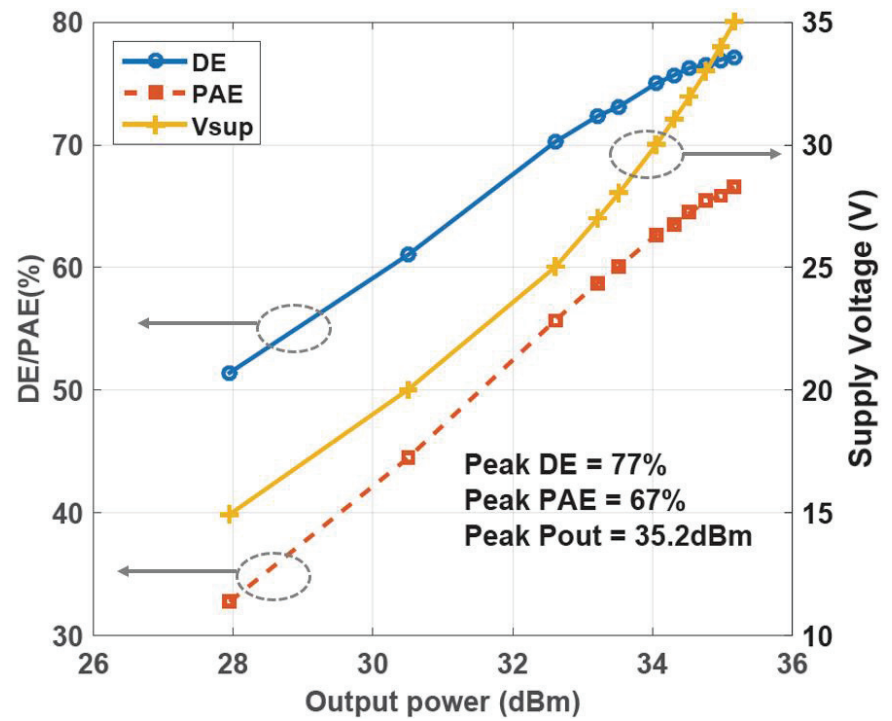

Fig. 20. Measured drain efficiency (DE) and power-added efficiency (PAE) of a single GaN Class-D PA under supply voltage variation between $15 \mathrm{~V}$ and $35 \mathrm{~V}$ without power combining.

LTE signals is higher than $12 \mathrm{~dB}$, which will decrease the $78 \%$ peak PAE into a very poor average PAE of below 5\%. Concerning efficiency, the key advantage of outphasing Class-S transmitter is not to increase the peak efficiency, but to increase the average efficiency at the expense of the peak efficiency.

\section{B. Digital Outphasing Transmitter}

Fig. 21 shows the output power, DE, and PAE of the outphasing Class-S transmitter, which consists of the two GaN Class-D PAs and a Chireix power combiner, with a fixed $35 \mathrm{~V}$ supply voltage while varying the outphasing angles between zero and 45 degrees. The prototype transmitter implements the MDPC scheme 1 (Table I) where all power codes can be transmitted with less than $45^{\circ}$ outphasing angles. Note that transmitter has $59 \% \mathrm{DE}$ and $50 \% \mathrm{PAE}$, which is $17-18 \%$ lower than the efficiencies before connecting the two Class-D PAs using a Chireix power combiner. When the outphasing angle is zero, the PA load impedance is designed to $35 \mathrm{ohm}$, which increases to $70 \mathrm{ohm}$ with 45 -degree outphasing angle. The susceptance adjustment to achieve high average efficiency is realized by the difference in the length of the transmission lines that connect the PAs to the combiner. This technique is introduced in [36] for Class-E PAs, providing a convenient way to precisely control the amount of susceptance compensation. Simulated DE from the analysis results in Section III-D shows good matching with the measured DE.

Fig. 22 shows the measured concurrent dual-band LTE signal from the prototype digital outphasing transmitter. $-37-\mathrm{dBc}$ ACPR is achieved with the 5-MHz bandwidth channel at $244 \mathrm{MHz}$ band while $-30-\mathrm{dBc}$ ACPR is achieved with the $10-\mathrm{MHz}$ bandwidth channel at $500 \mathrm{MHz}$ band. Compared to the transmitter output spectrum without the GaN PAs (with driver amplifiers only), there are 9-dB ACPR degradation in the low band and 13-dB ACPR degradation in the high band.

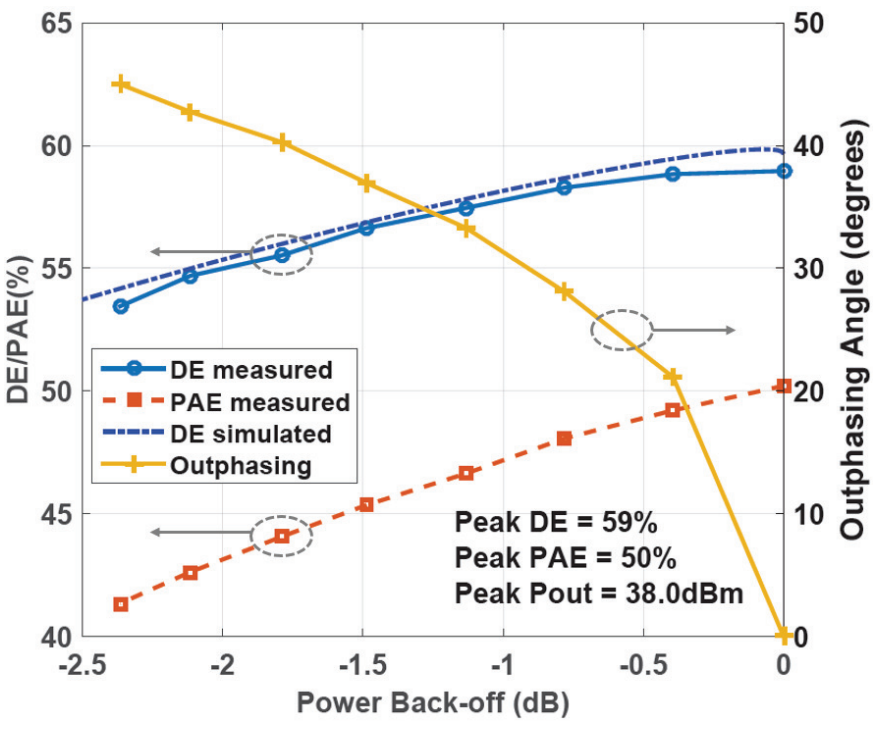

Fig. 21. Measured drain efficiency (DE) and power-added efficiency (PAE) of the Class-S outphasing transmitter using two GaN Class-D PAs with a fixed $35 \mathrm{~V}$ supply voltage and a Chireix power combiner for outphasing angles between 0 and 45 degrees.

Table IV lists measured performance summary of the prototype transmitter including other design/test parameters. The outphasing transmitter has $59.0 \%$ peak DE and $50.2 \%$ peak PAE with 38.0-dBm peak output power. The transmitter has $19.0 \%$ average DE and $14.8 \%$ average PAE with $27.1-\mathrm{dBm}$ average output power during concurrent dual-band LTE transmission, which is approximately four times higher than the $5 \%$ average DE that we can expect with an ideal Class-B PA for signals with 12-dB PAPR. The measured coding efficiency with the dual-band LTE signal transmission is $35.4 \%$. Although modulated signal tests have not been performed on a single Class-D PA, the average efficiency of the GaN Class-D PA for concurrent dual-band LTE transmission can be estimated from the measured coding efficiency of the related works [3],[5]. The average DE/PAE of a single Class-D PA for dual-band LTE transmission is expected to be less than $3 \%$ because the measured coding efficiency with other related works is less than $5 \%$ due to the excessive out-of-band noise from oversampling. The GaN Class-D PA shows $77.2 \%$ measured peak DE and $66.6 \%$ measured peak PAE with 35.2-dBm peak output power. The fact that the $19.0 \%$ measured average $\mathrm{DE}$ with the proposed transmitter is significantly higher than the $2-3 \%$ expected average DE with a single Class-D PA, confirms that the coding efficiency improvement by the proposed technique is significantly large enough to compensate for the power combiner loss.

Table V compares this work with other state-of-the-art concurrent multiband digital transmitters for inter-band carrier aggregation. As studied in [37], [38], oversampling digital transmitters based on delta-sigma modulation typically provides poor coding efficiency below $10 \%$ due to out-of-band noise. Although multilevel delta-sigma modulation for multilevel digital PAs can improve the coding efficiency, more than 3-5 levels are practically not possible due to hardware 


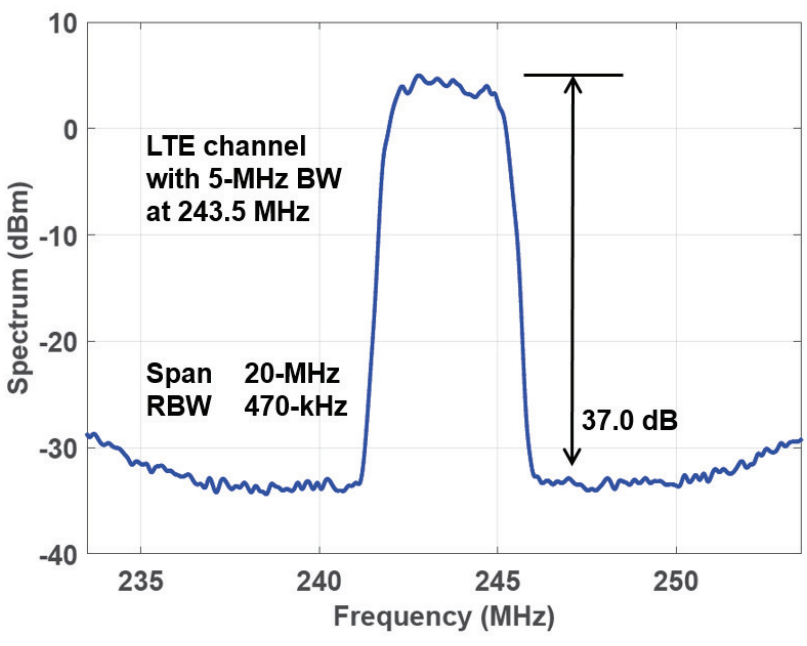

(a)

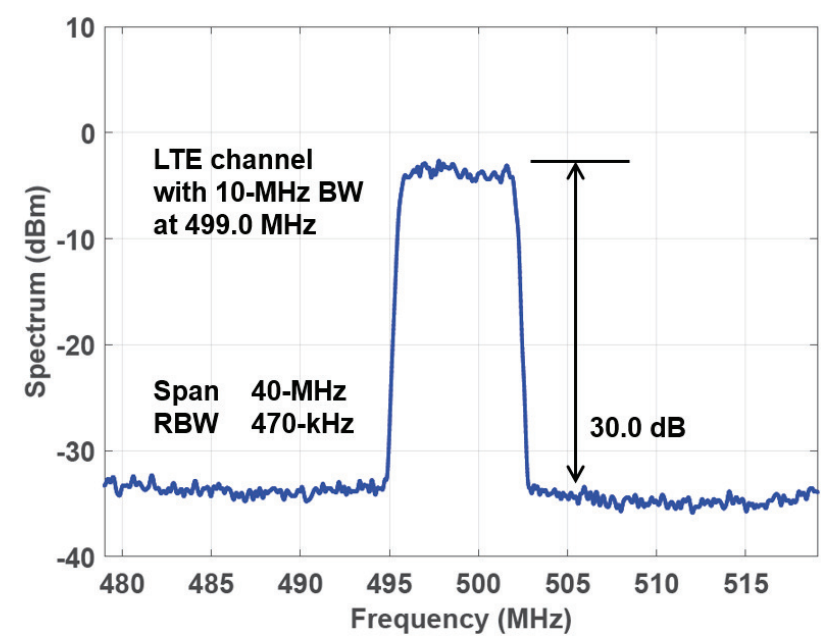

(b)

Fig. 22. Measured concurrent dual-band LTE transmission (a) low-band with $5-\mathrm{MHz}$ channel bandwidth at $240 \mathrm{MHz}$ band, (b) high-band with $10-\mathrm{MHz}$ channel bandwidth at $500 \mathrm{MHz}$ band.

complexity and increased parasitic capacitances. Experimental [41] and simulation [37] studies show that coding efficiency with 3-level delta-sigma modulation stays below $10 \%$ while 5-level modulation stays below $30 \%$. Although the previous work reported in [4] shows over $40 \%$ coding efficiency, since it requires an 8-way parallel structure, the hardware complexity is equivalent to a 6-level digital transmitter. The prototype digital outphasing transmitter with GaN Class-D PAs achieves higher than $30 \%$ coding efficiency because the outphasing virtually increases the number of PWM signal levels. If the outphasing is not applied, the prototype digital transmitter will be effectively the same as a 3-level digital transmitter, which may not achieve higher than $10 \%$ coding efficiency.

Concerning digital power consumption, one important factor, which determines the digital power consumption, is the digital sampling clock rate. Table V in Section IV-B shows the
TABLE IV

PROTOTYPE CONCURRENT DUAL-BAND DIGITAL OUTPHASING TRANSMITTER DESIGN PARAMETERS AND MEASUREMENT SUMMARY

\begin{tabular}{|c|c|}
\hline Low-band channel & $244 \mathrm{MHz}$ \\
\hline High-band channel & $500 \mathrm{MHz}$ \\
\hline Channel BW at low-band & $5 \mathrm{MHz}$ \\
\hline Channel BW at high-band & $10 \mathrm{MHz}$ \\
\hline Low-band test signal & LTE w/ $11.0 \mathrm{~dB}$ PAPR \\
\hline High-band test signal & LTE w/ 11.7 dB PAPR \\
\hline PA 3-dB bandwidth & $1.0 \mathrm{GHz}$ \\
\hline Combiner 3-dB bandwidth & $4.9 \mathrm{GHz}$ \\
\hline Driver amp low-band ACPR & $-46 \mathrm{dBc}$ \\
\hline Driver amp high-band ACPR & $-43 \mathrm{dBc}$ \\
\hline TX Low-band ACPR & $-37 \mathrm{dBc}$ \\
\hline TX High-band ACPR & $-30 \mathrm{dBc}$ \\
\hline Baseband signal sampling rate & $61.44 \mathrm{MHz}$ \\
\hline BPDSM sampling rate & $2.15 \mathrm{GHz}$ \\
\hline MDPC sampling rate & $8.6 \mathrm{GHz}$ \\
\hline \# of BPDSM output levels & 5 \\
\hline \# of MDPC output levels & 2 \\
\hline Coding efficiency & $35.4 \%$ \\
\hline PA peak output power & $35.2 \mathrm{dBm}$ \\
\hline PA peak efficiency & DE $77.2 \%$ / PAE $66.6 \%$ \\
\hline TX peak output power & $38.0 \mathrm{dBm}$ \\
\hline TX peak efficiency & DE $59.0 \%$ / PAE $50.2 \%$ \\
\hline TX avg. output power & $27.1 \mathrm{dBm}$ \\
\hline TX avg. efficiency & DE $19.0 \%$ / PAE $14.8 \%$ \\
\hline
\end{tabular}

digital sampling rate of related works. The most of the previous works need a digital sampling clock rate approximately 4 times higher than the highest carrier frequency. To simplify implementation, we used a digital sampling clock frequency approximately 16 times higher than the high-band channel frequency. By using an open-loop phase modulator, such as reported in [42], 4 times higher digital sampling rate will be sufficient with our prototype. Therefore the power consumption for the digital signal processing with the proposed architecture is deemed comparable to the conventional digital transmitters based on bandpass delta-sigma modulation. Digital transmitters [21], [41] with a similar level of complexity and performance for digital processing indicates that the power consumption for the digital signal processing with the proposed transmitter architecture can be justified with output power larger than $100 \mathrm{~mW}$.

It should be noted that using RFPWM with BPDSM in the proposed architecture is not an overhead; RFPWM only transmitters require PWM sampling rate more than 100 times higher than the highest carrier frequency $(50 \mathrm{GHz})$, which is not practical to implement. A 3-level BPDSM only transmitter, according to behavioral simulation, only $8.6 \%$ coding efficiency is achieved with the same dual-band transmission. 
TABLE V

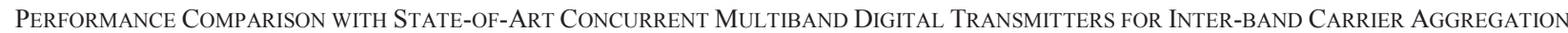

\begin{tabular}{|c|c|c|c|c|c|c|}
\hline Ref. / Year & [2] / 2008 & [3] / 2010 & {$[4] / 2013$} & {$[5] / 2013$} & This work & This work \\
\hline Digital TX Architecture & $\begin{array}{r}\text { LPDSM } \\
+ \text { Digital } \\
\text { Up-conversion }\end{array}$ & $\begin{array}{r}\text { BPDSM } \\
+ \text { Digital } \\
\text { Up-conversion }\end{array}$ & $\begin{array}{r}\text { LPDSM } \\
+ \text { Digital } \\
\text { Up-conversion } \\
+ \text { Multipath } \\
\end{array}$ & $\begin{array}{l}\text { Multiband } \\
\text { BPDSM }\end{array}$ & $\begin{array}{r}\text { Multiband } \\
\text { BPDSM } \\
+ \text { RFPWM } \\
+ \text { Outphasing } \\
\end{array}$ & $\begin{array}{r}\text { Multiband } \\
\text { BPDSM } \\
+ \text { RFPWM } \\
+ \text { Outphasing } \\
\end{array}$ \\
\hline Low-band Channel & $300 \mathrm{MHz}$ & $800 \mathrm{MHz}$ & $781 \mathrm{MHz}$ & $800 \mathrm{MHz}$ & $856 \mathrm{MHz}$ & $244 \mathrm{MHz}$ \\
\hline High-band Channel & $2500 \mathrm{MHz}$ & $2000 \mathrm{MHz}$ & $1250 \mathrm{MHz}$ & $1500 \mathrm{MHz}$ & $1450 \mathrm{MHz}$ & $500 \mathrm{MHz}$ \\
\hline Channel BW at Low-band & $0.5 \mathrm{MHz}$ & $5 \mathrm{MHz}$ & $1.5 \mathrm{MHz}$ & $5 \mathrm{MHz}$ & $20 \mathrm{MHz}$ & $5 \mathrm{MHz}$ \\
\hline Channel BW at High-band & $0.5 \mathrm{MHz}$ & $10 \mathrm{MHz}$ & $1.25 \mathrm{MHz}$ & $5 \mathrm{MHz}$ & $20 \mathrm{MHz}$ & $10 \mathrm{MHz}$ \\
\hline Aggregate Channel BW & $1 \mathrm{MHz}$ & $15 \mathrm{MHz}$ & $2.75 \mathrm{MHz}$ & $10 \mathrm{MHz}$ & $40 \mathrm{MHz}$ & $15 \mathrm{MHz}$ \\
\hline Low-band Test Signal & OFDM 16-QAM & QPSK & WiMAX & LTE & LTE & LTE \\
\hline High-band Test Signal & OFDM 16-QAM & QPSK & 64-QAM & LTE & LTE & LTE \\
\hline Low-band PAPR & N/A & $6 \mathrm{~dB}$ & $7 \mathrm{~dB}$ & $6.5 \mathrm{~dB}$ & $11.7 \mathrm{~dB}$ & $11.0 \mathrm{~dB}$ \\
\hline High-band PAPR & N/A & $6 \mathrm{~dB}$ & $8 \mathrm{~dB}$ & $6.5 \mathrm{~dB}$ & $11.7 \mathrm{~dB}$ & $11.7 \mathrm{~dB}$ \\
\hline TX Low-band ACPR & $-40 \mathrm{dBc}$ & $-50 \mathrm{dBc}$ & $-42 \mathrm{dBc}$ & $-50 \mathrm{dBc}$ & $-45 \mathrm{dBc}$ & $-37 \mathrm{dBc}$ \\
\hline TX High-band ACPR & $-42 \mathrm{dBc}$ & $-50 \mathrm{dBc}$ & $-48 \mathrm{dBc}$ & $-48 \mathrm{dBc}$ & $-43 \mathrm{dBc}$ & $-30 \mathrm{dBc}$ \\
\hline Digital Sampling Rate & $200 \mathrm{MHz}$ & $8 \mathrm{GHz}$ & $5 \mathrm{GHz}$ & $3.9 \mathrm{GHz}$ & $25 \mathrm{GHz}$ & $8.6 \mathrm{GHz}$ \\
\hline \# of Digital TX Output Levels & 2 & 2 & 3 & 2 & 3 & 2 \\
\hline PA Included? & No & No & No & No & No & Yes \\
\hline TX Output Filter Considered? & No & Yes & No & No & Yes & No \\
\hline Measured TX Peak Output Power & N/A & $\mathrm{N} / \mathrm{A}$ & N/A & N/A & N/A & $38.0 \mathrm{dBm}$ \\
\hline Measured TX Avg. Output Power & N/A & N/A & N/A & N/A & N/A & $27.1 \mathrm{dBm}$ \\
\hline Measured TX Coding Efficiency & $<10 \%$ & $<5 \%$ & $46.3 \%$ & $<5 \%$ & $47.1 \%$ & $35.4 \%$ \\
\hline Measured TX Avg. Mod. Efficiency & $\mathrm{N} / \mathrm{A}$ & N/A & N/A & N/A & $\mathbf{N} / \mathbf{A}$ & $\begin{array}{r}\text { DE } 19.0 \% \\
\text { PAE } 14.8 \% \\
\end{array}$ \\
\hline
\end{tabular}

\section{CONCLUSION}

A digital outphasing transmitter architecture is designed and implemented for concurrent multiband transmission to support high data rate applications. Digital outphasing increases the effective number of RF PWM output levels, approximately doubling the coding efficiency compared to the conventional digital transmitters using the same Class-S PAs. A prototype transmitter with 2-level bipolar RF PWM achieves coding efficiency comparable to 5-level RF PWM transmitters by digitally controlling the outphasing angle. By using a small number of different outphasing angles, the PA mismatch sensitivity is reduced. In the digital outphasing transmitters, which exploit both PWM and outphasing, there are additional degree-of-freedoms in RF envelope modulation. Digital outphasing, therefore, needs to modulate the transmitter output envelope only with a small dynamic range. These new features allow the digital outphasing transmitter to use a Chireix power combiner, which has high power combining efficiency but with limited dynamic range.

The concept of multidimensional power coding (MDPC) is introduced, which allows the digital transmitter designers to explore the important design trade-off between the transmitter linearity and coding efficiency. We discussed outphasing 2-level RFPWM as an example of linear but inefficient coding scheme and outphasing 3-level RFPWM as the opposite case of nonlinear but efficient coding scheme. As a proof-of-concept, outphasing 2-level RFPWM is implemented in the prototype digital outphasing transmitter. Further work on the baseband digital predistortion, which considers both static and dynamic nonlinearity of switching-mode PAs, will deploy the power coding schemes that are nonlinear but has high coding efficiency.

\section{ACKNOWLEDGMENT}

The authors would like to thank Jin Shao at the University of North Texas, for his work on the multi-band filter and Chireix power combiner during his internship at Mitsubishi Electric Research Laboratories. The authors would like to thank Toshiaki Koike-Akino and Koji Yamanaka at Mitsubishi Electric for their valuable advice and technical support.

\section{REFERENCES}

[1] 3GPP TR36.850-V11.1.0 Inter-Band Carrier Aggregation, $3^{\text {rd }}$ Generation Partnership Project, Jul. 2013.

[2] M. Helaoui, S. Hatami, R. Negra, and F. M. Ghannouchi, "A novel architecture of delta-sigma modulator enabling all-digital multiband multistandard RF transmitter design," IEEE Trans. Circuits Syst. II: Exp. Briefs, vol. 55, no. 11, pp. 1129-1133, Nov. 2008.

[3] T. Kitayabu, Y. Amano, and H. Ishikawa, "Concurrent dual-band transmitter architecture for spectrum aggregation system," in Proc. IEEE Radio and Wireless Symposium, Jan. 2010, pp. 689-692. 
[4] N. V. Silva, A. S. R. Oliveira, and N. B. Carvalho, "Design and optimization of flexible and coding efficient all-digital RF transmitters," IEEE Trans. Microw. Theory Techn., vol. 61, no. 1, pp. 625-632, Jan. 2013.

[5] T. Maehata, K. Totani, S. Kameda, and N. Suematsu, "Concurrent dual-band 1-bit digital transmitter using band-pass delta-sigma modulator," in Proc. IEEE European Microw. Conf., Oct. 2013, pp. 1523-1526.

[6] F. H. Raab, "Radio frequency pulse width modulation," IEEE Trans. Comm., vol. 21, no. 8, pp. 958-966, Aug. 1973.

[7] F. H. Raab, "Class-D power amplifier with RF pulse-width modulation," in Proc. IEEE MTT-S Int. Microw. Symp., May 2010, pp. 924-927.

[8] R. Leberer, R. Reber, and M. Oppermann, "An AlGaN/GaN Class-S amplifiers for RF-communication signals," in Proc. IEEE MTT-S Int. Microw. Symp., June 2008, pp. 85-88.

[9] A. Wentzel, C. Meliani, and W. Heinrich, "RF Class-S power amplifiers: state-of-the-art results and potential," in Proc. IEEE MTT-S Int. Microw. Symp., May 2010, pp. 812-815.

[10] T.-P. Hung, J. Rode, L. E. Larson, and P. M. Asbeck, "Design of H-bridge Class-D power amplifiers for digital pulse modulation transmitters," IEEE Trans. Microw. Theory Techn., vol. 55, no. 11, pp. 2845-2855, Dec. 2007

[11] T. Blocher and P. Singerl, "Coding efficiency for different switched-mode RF transmitter architectures," in Proc. IEEE Int. Midwest Symp. Circ. Syst., Aug. 2009, pp. 276-279.

[12] S. Chi, P. Singerl, and C. Vogel, "Efficiency optimization for burst-mode multilevel radio frequency transmitters," IEEE Trans. Circ. Syst. I: Reg. Papers, vol. 60, no. 7, pp. 1901-1914, Jul. 2013.

[13] T. Johnson and S. P. Stapleton, "Comparison of bandpass $\Sigma \Delta$ modulator coding efficiency with a periodic signal model," IEEE Trans. Circ. Syst. I: Reg. Papers, pp. 3763-3775, Dec. 2008.

[14] W. Chen, S. A. Bassam, X. Li, Y. Liu, K. Rawat, M. Helaoui, and F. M. Ghannouchi, "Design and linearization of concurrent dualband Doherty power amplifier with frequency dependent power ranges," IEEE Trans. Microw. Theory Techn., vol. 59, no. 10, pp. 2537-2546, Oct. 2011.

[15] P. Saad, P. Colantonio, L. Piazzon, F. Giannini, K. Andersson, and C. Fager, "Design of a concurrent dual-band 1.8-2.4-GHz GaN HEMT Doherty power amplifier," IEEE Trans. Microw. Theory Techn., vol. 60, no. 6, pp. 1840-1849, June 2012.

[16] A. Grebennikov and J. Wong, "A dual-band parallel Doherty power amplifier for wireless applications," IEEE Trans. Microw. Theory Techn., vol. 60 , no. 10 , pp. 3214-3222, Oct. 2012.

[17] M. Nielsen and T. Larsen, "A 2-GHz GaAs HBT RF pulsewidth modulator," IEEE Trans. Microw. Theory Techn.,vol. 56, no. 2, pp. 300304, Feb. 2008.

[18] J. Choi, J. Yim, J. Yang, J. Kim, J. Cha, D. Kang, D. Kim, and B. Kim, “A $\Delta \Sigma$-digitized polar RF transmitter," IEEE Trans. Microw. Theory Techn., vol. 55, no. 12, pp. 2679-2690, Dec. 2007

[19] Q. Zhu, R. Ma, C. Duan, K. H. Teo, and K. Parsons, "A 5-level discrete-time power encoder with measured coding efficiency of $70 \%$ for 20-MHz LTE digital transmitter," in Proc. IEEE MTT-S Int. Microw. Symp., 2014.

[20] Z. Ye, J. Grosspietsch, and G. Memik, "An FPGA based all-digital transmitter with radio frequency output for software defined radio," in Proc. Design, Automation, and Test in Europe, Apr. 2007, pp. 1-6.

[21] R. Hezar, L. Ding, J. Hur, and B. Haroun, "A $23 \mathrm{dBm}$ fully digital transmitter using $\Delta \Sigma$ and pulse-width modulation for LTE and WLAN application in 45nm CMOS," in Proc. IEEE Radio Freq. Integ. Circ. Symp., June 2014, pp. 217-220.

[22] J.-C. Park, J.-G. Yook, B. H. Park, N. Jeon, K.-S. Seo, D. Kim, W.-S. Lee, and C.-S. Yoo, "Hybrid current-mode class-S power amplifier with GaN Schottky diode using chip-on-board technique for $955 \mathrm{MHz}$ LTE signal," IEEE Trans. Microw. Theory Techn., vol. 61, no. 12, pp. 4168-4178, Dec. 2013.

[23] S. Chung, R. Ma, K. H. Teo, and K. Parsons, "Outphasing multi-level RF-PWM signals for inter-band carrier aggregation in digital transmitters," to appear in IEEE Radio Wireless Symp., Jan. 2015.

[24] T. W. Barton, J. L. Dawson, and D. J. Perreault, "Experimental validation of a four-way outphasing combiner for microwave power amplification," IEEE Microw. Wireless Compon. Lett., vol. 23, no. 1, pp. 28-30, Jan. 2013.

[25] M. E.-Asmar, A. Birafane, M. Helaoui, A. B. Kouki, and F. M. Ghannouchi, "Analytical design methodology of outphasing amplification systems using a new simplified Chireix combiner model,"
IEEE Trans. Microw. Theory Techn., vol. 60, no. 6, pp. 1886-1895, Jun. 2012.

[26] A. Birafane, and A. B. Kouki, "On the linearity and efficiency of outphasing microwave amplifiers," IEEE Trans. Microw. Theory Techn., vol. 52, no. 7, pp. 1702-1708, Jul. 2004.

[27] M. Ozen, C. M. Andersson, T. Eriksson, M. Acar, R. Jos, and C. Fager, "Linearization study of a highly efficieny CMOS-GaN RF pulse width modulation based transmitter," in Proc. IEEE Euro. Microw. Symp., Nov. 2012.

[28] F. Raab, "Class-D power amplifier with RF pulse-width modulation," in Proc. IEEE MTT-S Int. Microw. Symp., May 2010, pp. 924-927.

[29] S. Chung, P. A. Godoy, T. W. Barton, D. J. Perreault, and J. L. Dawson, "Asymmetric multilevel outphasing transmitter using class-E PAs with discrete pulse width modulation," in Proc. IEEE MTT-S Int. Microw. Symp., Jun. 2010, pp. 264-267.

[30] J.-H. Chen, "An efficiency-improved outphasing power amplifier using RF pulse modulation," IEEE Microw. Wireless Compon. Lett., vol. 20 , no. 12, pp. 684-686, Dec. 2010.

[31] R. Schreier, Understanding Delta-Sigma Data Converters, IEEE Press, 2005

[32] D. Markert, C. Haslach, H. Heimpel, A. Pascht, and G. Fisher, "Phase-modulated DSM-PWM hybrids with pulse length restriction for switch-mode power amplifiers," in Proc. Euro. Microw. Integrated Circ. Conf., Oct 2014, pp. 420-423.

[33] J. Yao and S. I. Long, "Power amplifier selection for LINC applications," IEEE Trans. Circ. Syst. II: Express Papers, vol. 53, no. 8, pp. 763-767, Aug. 2006.

[34] J. H. Qureshi, M. J. Pelk, M. Marchetti, W. C. E. Neo, J. R. Gajadharsing, M. P. van der Heijin, and L. C. N. de Vreede, "A 90-W peak power GaN outphasing amplifier with optimum input signal conditioning," IEEE Trans. Microw. Theory Techn., vol. 57, no. 8, pp. 1925-1935, Aug. 2009.

[35] H. Xu, Y. Palaskas, A. Ravi, M. Sajadieh, M. A. El-Tanari, and K. Soumyanath, "A flip-chip-packaged $25.3 \mathrm{dBm}$ Class-D outphasing power amplifier in 32nm CMOS for WLAN application," IEEE J. Solid State Circ., vol. 46, no. 7, pp. 1596-1605, Jul. 2011.

[36] R. Beltran, F. H. Raab, and A. Velazquez, "HF outphasing transmitter using Class-E power amplifiers," in Proc. IEEE MTT-S Int. Microw. Symp., Jun. 2009, pp. 757-760.

[37] M. M. Ebrahimi, M. Helaoui, F. M. Ghannouchi, "Improving coding efficiency by compromising linearity in delta-sigma based transmitters," in Proc. IEEE Radio and Wireless Symposium, Jan. 2012, pp. 411-414.

[38] M. M. Ebrahimi, M. Helaoui, F. M. Ghannouchi, "Delta-sigma based transmitters," IEEE Microw. Mag, vol. 14, no. 1, pp. 68-78, Jan. 2013.

[39] Y. P. Zhang and M. Sun, "Dual-band microstrip bandpass filter using stepped-impedance resonators with new coupling schemes," IEEE Trans. Microw. Theory Techn., vol. 54, no. 10, pp.3779-3785, Oct. 2006

[40] H. Nakamizo, K. Mukai, S. Shinjo, H. Gheidi, and P. Asbeck, "Over 65\% PAE GaN voltage-mode Class D power amplifier for $465 \mathrm{MHz}$ operation using bootstrap drive," to appear in IEEE Radio Wireless Week, Jan. 2015.

[41] P. Godoy, S. Chung. T. W. Barton, D. J. Perreault, and J. L. Dawson, “A 2.4-GHz, 27-dBm asymmetric multilevel outphasing power amplifier in 65nm CMOS," IEEE J. Solid State Circ., vol. 47, no. 10, pp. 2372-2383, Oct. 2012

[42] A. Ravi, P. Madoglio, H. Xu, K. Chandrashekar, M. Verhelst, S. Pellerano, L. Cuellar, M. A.-Hernandez, M. Sajadieh, J. E. Z.-Roldan, O. B.-Degani, H. Lakdawala, and Y. Palaskas, "A 2.4-GHz 20-40-MHz channel WLAN digital outphasing transmitter utilizing a delay-based wideband phase modulator in 32-nm CMOS," IEEE J. Solid State Circ., vol. 47, no. 12, pp. 3184-3196, Dec. 2012. 


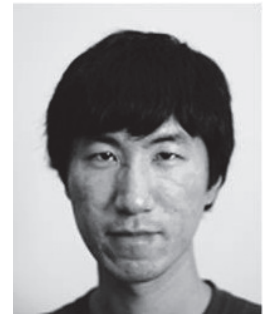

SungWon Chung (M'14) received his degrees all in electrical engineering, the B.S. degree from Pusan National University, Pusan, Korea, in 2002, the M.S. degree from KAIST, Daejeon, Korea, in 2005, and the Ph.D. degree from the Massachusetts Institute of Technology (MIT), Cambridge, MA, in 2014.

During the summer of 2008, he was an Intern at Intersil, Milpitas, CA, working on high-speed communication transceiver design. In 2014, he was an Intern at Mitubishi Electric Research Laboratories (MERL), Cambridge, MA, working on digital transmitter and wideband GaAs power amplifier design. Since 2014, he has been a Postdoctoral Fellow at the University of Southern California, Los Angeles, CA, and a Research Affiliate at MIT Microsystems Technology Laboratories (MTL), Cambridge, MA. He was a Postdoctoral Associate at MIT MTL working on mixed-signal GaN circuit design in 2014. His research interests include circuit and system design for mobile communication.

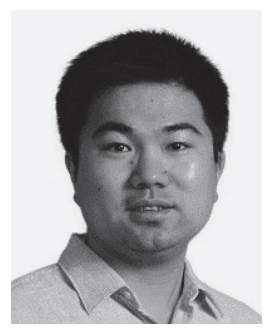

Rui Ma received the B.Eng. degree from Xi'an Jiaotong Univerisity, Xi' an, China in 2004, M.S. and Dr.-Ing. degree in electrical engineering from Kassel University, Kassel Germany in 2006 and 2009, respectively. From 2007-2010, he was with the Microwave Electronics Labs at Kassel University as research fellow working on the transistor modeling and RF power amplifiers design. From 2010-2012, he was a senior research engineer with Nokia Siemens Networks (NSN), where he focused on the R\&D of enabling RF techniques for wideband radio at NSN CTO Research in Beijing, China. Since 2012, he is with Mitsubishi Electric Research Laboratories (MERL) in Cambridge, MA, USA. Currently, he is the principal research scientist for RF technologies, focusing on multi-mode multi-band (MMMB) power amplifiers, advanced digital transmitter for mobile communications, as well as emerging applications of GaN. In 2013, Dr. Ma was awarded the specification award by MIPI Alliance for the contribution to the development of Analog Reference Interface (ACI) for Envelope Tracking eTrak specification.

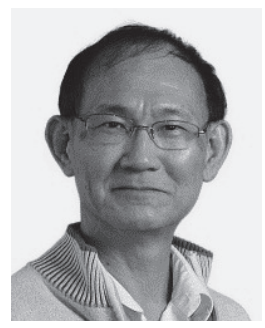

Koon Hoo Teo received his M.S. and Ph.D. degrees in electrical engineering from the University of Alberta, Edmonton, Canada, in 1985 and 1990, respectively. He was with Nortel Networks for about 15 years where his main $R \& D$ thrusts were in $3 \mathrm{G}$ and 4G Wireless Communication Systems and Mesh Networks. He is currently with Mitsubishi Electric Research Labs, Cambridge, MA, USA. He is one of the main authors of ANSI C63.17 for the unlicensed bands and a contributor to WiMAX and LTE standards in the PHY and MAC layers. He is also the author and co-author of over 75 reviewed papers and 125 granted patents and patent applications which span a range of areas that include Nano and Surface Physics, Semiconductor Power Devices, Metamaterial, Optical and Wireless Communications, Cognitive Radio, Game Theory, RF and Power Electronics, Battery Charging and Wireless Power Transfer. Dr. Teo is a recipient of the Nortel Innovation Award.

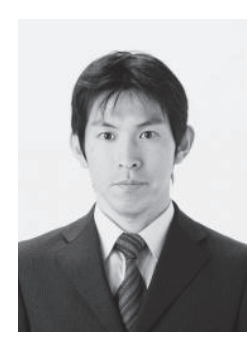

Shintaro Shinjo received the B.S. and M.S. degrees in Physics, and Ph.D. degrees in Engineering from Keio University, Kanagawa, Japan, in 1996, 1998 and 2011, respectively. In 1998, he joined Mitsubishi Electric Corporation, where he has been engaged in the research and development of Microwave Monolithic Integrated Circuits and Solid-state Power Amplifiers. From 2011 to 2012, he was a visiting scholar at the University of California, San Diego. Dr. Shinjo is a senior member of the Institute of Electronics, Information and Communication Engineers (IEICE) of Japan. He was the recipient of the Prize for Science and Technology (Development Category) of the Commendation for Science and Technology by the Minister of Education, Culture, Sports, Science and Technology in 2009 and IEICE Electronics Society Award in 2011.

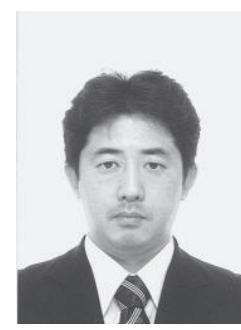

Hideyuki Nakamizo received the B.S. and M.S. degrees in science from Tsukuba University, Tsukuba, Japan, in 1997 and 1999, respectively. In 1999, he joined Mitsubishi Electric Corporation, where he has been engaged in research and development of transceivers for mobile communications and radar systems. From 2013 to 2014, he was a visiting scholar at the University of California, San Diego. Mr. Nakamizo is a member of the Institute of Electronics, Information and Communication Engineers (IEICE) of Japan.

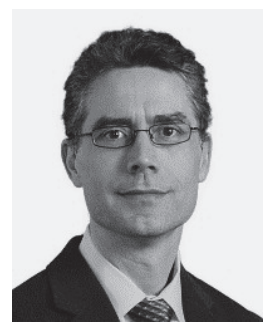

Kieran Parsons received B.Eng. and Ph.D. degrees in Electronic and Communications Engineering from the University of Bristol, UK, in 1992 and 1996, respectively. From 1997-2002 he was with Nortel Networks, Ottawa, Canada, where he worked on wireless and long-haul optical communications system architecture and design. From 2004-2006 he worked on carrier-grade mesh WiFi RF system design at BelAir Networks (now part of Ericsson) and from 2006-2009 on 10G PHY device development with Applied Micro, both in Kanata, Canada. In 2009, he joined Mitsubishi Electric Research Laboratories (MERL) in Cambridge, MA, USA, where he is currently Group Manager. 